\title{
Article
}

\section{Rethinking Informed Consent}

\author{
Peter H. Schuck ${ }^{\dagger}$
}

\section{CONTENTS}

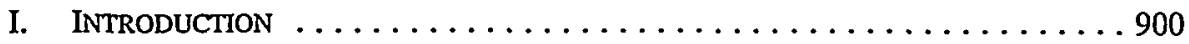

II. CONSENT IN CONTEMPORARy TORT LAW $\ldots \ldots \ldots \ldots$. . . . . . . 907

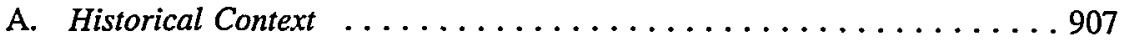

B. Doctrinal Context ......................... . . 909

1. Tort Law Generally ................... 910

2. Products Liability ..................... 913

3. Informed Consent Proper ................. 916

III. Consent in Health Care Treatment Decisions:

A Comparative AnALYSIS . . . . . . . . . . . . . . . 920

A. The Doctrines Compared . . . . . . . . . . . . . . . . 921

B. Can the Greater Informed Consent Burden on Physicians Be Justified? . 924

1. The Argument from Individual Autonomy . . . . . . . . . . 924

2. The Argument from Relational Continuity ........... 926

$\dagger$ Simeon E. Baldwin Professor of Law and Deputy Dean, Yale Law School. The author wishes to acknowledge the useful comments he received on earlier versions of this Article from Yale Law School colleagues, especially Dr. Jay Katz and Robert Burt, at a faculty workshop in March 1993. Randall Bovbjerg, Dr. Ralph Horwitz, Dr. Jonathan Katz, Susan Katz, Dr. Robert Levine, and Dr. Sherwin Nuland also provided valuable comments. Matthew D'Amore furnished fine research assistance. An earlier version of this Article was presented at a conference on "The Rights of Patients in the Health Care System" held in Orenas Castle, Sweden on April 21-25, 1993 and will appear as a chapter in PATIENTS' RIGHTS: INFORMED CONSENT, ACCESS AND EQUALITY, (Phillips ed., forthcoming 1994). 
3. The Argument from Conflict of Interest . . . . . . . . . . 927

4. The Argument from Inequality of Information and Power . . . . . 928

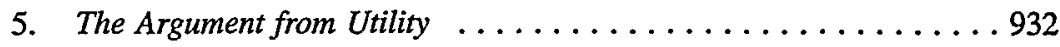

C. Would a More Demanding Informed Consent Doctrine

Be Worth the Cost? . . . . . . . . . . . . . . . 938

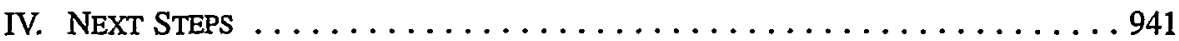

A. Cost-Effectiveness Analysis $\ldots \ldots \ldots \ldots \ldots \ldots \ldots \ldots \ldots \ldots . \ldots . \ldots \ldots 2$

B. Communicating Risk Information . . . . . . . . . . . . . 948

C. Contextualizing and Differentiating Informed Consent . . . . . . . . 951

D. Contracting About Levels of Informed Consent . . . . . . . . . . 956

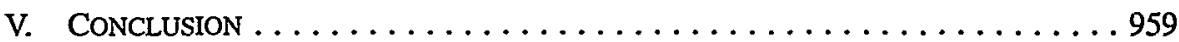

\section{INTRODUCTION}

The doctrine requiring physicians to obtain a patient's informed consent before undertaking treatment is relatively young, having first appeared in a recognizable, relatively robust form only in $1957 .{ }^{I}$ Yet the values that underlie the doctrine have an ancient pedigree. The consent norm had occupied a prominent and honored place in our legal thought for many centuries before the courts began to develop a jurisprudence of informed consent in health care. $^{2}$ Also well established was the cognate notion that consent must be informed or knowledgeable in some meaningful sense if we are to accord it legal or moral significance. ${ }^{3}$

Consent is the master concept that defines the law of contracts in the United States. First, consent expresses the primacy of individualistic values in our culture. To say that one cannot be bound by a promise that one did not voluntarily and knowingly make is to say that the individual should be the author of her own undertakings, that a genuine respect for her dignity requires a broad deference to her choices. It is to say that she alone can define the nature of her relationships with others-except to the extent that the state is

1. See JAy Katz, The Silent World of Doctor AND Patient $48-84$ (1984); see also Ruth R. FADEN \& TOM L. BEAUCHAMP, A HISTORY AND THEORY OF INFORMED CONSENT 235-73 (1986).

In this Article, I often refer to "physicians" rather than the more generic category "health care providers," although the informed consent obligation applies to anyone who undertakes treatment.

2. See, e.g., Ford v. Ford, 10 N.E. 474, 475 (Mass. 1887) ("[T] he absence of lawful consent is part of the definition of an assault.") (citing Christopherson v. Bare, 116 Eng. Rep. 554, 556 (1848)). For a discussion of the traditional role of the consent doctrine in health care, see O'Brien v. Cunard S.S. Co., 28 N.E. 266 (Mass. 1891), Bennan v. Parsonnet, 83 A. 948 (N.J. 1912), and Hively v. Higgs, 253 P. 363 (Or. 1927).

3. See, e.g., Choctaw, Okla. \& Gulf Ry. v. Jones, 92 S.W. 244, 248 (Ark. 1906); Baer v. Baird Mach. Co., 79 A. 673, 675 (Conn. 1911); Fitzgerald v. Connecticut River Paper Co., 29 N.E. 464 (Mass. 1891); Zurich Gen. Accident \& Liab. Ins. Co. v. Childs Co., 171 N.E. 391, 392 (N.Y. 1930). 
prepared to exercise its coercive regulatory authority by forcing her into, or redefining, such relationships.

Second, consent is instrumental to economic efficiency, a cherished value in American culture. According to neoclassical theory, which continues to dominate most academic thinking, a transaction increases one's welfare (and indirectly, social welfare) only when it results from one's informed, voluntary choice to engage in the transaction, or when it accurately mimics the choice that one would have made under those ideal conditions. ${ }^{4}$ Ordinarily, these transactions are effected and choices satisfied through markets.

A third foundation for consent in American law more generally is our abiding, almost obsessive suspicion of state power. Even today, sixty years after the New Deal established the structure of the administrative state, American political culture still presumes that the most legitimate ground for binding individuals is their consent to the transaction. As a matter of political rhetoric, the state may overcome this presumption in favor of private ordering only by explicitly justifying the intrusion of public law. ${ }^{5}$

The Supreme Court drew together these three threads of informed consent-individual autonomy, economic efficiency, and anti-statism-in its famous 1905 decision, Lochner v. New York, ${ }^{6}$ in which the Court invalidated a state law prescribing maximum hours and working conditions for bakery employees. The Due Process Clause, the Court held, proscribed state law limits on employers' and employees' liberty of contract, understood as their mutual, voluntary consent to the terms of employment. ${ }^{7}$ Although the Court thereafter jettisoned liberty of contract as a constitutional norm, ${ }^{8}$ the conception of individual autonomy that Lochner sought to advance survives in a number of public health contexts, such as federal regulation of research on human subjects, ${ }^{9}$ mandated disclosures for patients whose care is financed under federal programs, ${ }^{10}$ and other statutorily required disclosures. ${ }^{11}$

4. See generally Paul A. Samuelson \& William D. NoRdhaus, ECONOMics 41 (14th ed. 1992) ("[Efficient exchanges] are made through voluntary exchange of goods for money at market prices .....").

5. This presumption is revealed, for example, in the recent policy debates over the Family and Medical Leave Act of 1993, Pub. L. No. 103-3, 107 Stat. 6 (1993) (amending 2 U.S.C. \$§ 60m-60n (1988); 5 U.S.C. $\S \S 6381-6386$ (1988); 29 U.S.C. $\$ \S 2601-2654$ (1988)). A major issue in the debates was whether individual employers and employees should be coerced by the government into adopting leave arrangements to which one or both did not consent. See, e.g., Helen Dewar, Senate Panel Relaunches Family Leave Legislation, WASH. POST, Apr. 25, 1991, at A13.

6. 198 U.S. 45 (1905).

7. Id. at 52-65.

8. See, e.g., United States v. Darby, 312 U.S. 100 (1941) (upholding Fair Labor Standards Act); West Coast Hotel Co. v. Parrish, 300 U.S. 379 (1937) (upholding minimum wage legislation); NLRB v. Jones \& Laughlin Steel Corp., 301 U.S. 1 (1937) (upholding National Labor Relations Act).

9. 45 C.F.R. $\$ 46.116-46.117$ (1992) (describing mandated disclosures and documentation).

10. For example, the Public Health Service's program to grant states funds for substance abuse and HIV early intervention requires states to provide informed consent to persons seeking early intervention through such programs. 42 U.S.C.A. $\$ 300 x-24(b)(6)(A)$ (West Supp. 1993). Informed consent is also required for care provided by the Veterans Health Administration. 38 U.S.C.A. \$ 7331 (West Supp. 1993). Under the Patient Self-Determination Act, 42 U.S.C.S. $\$ 1396$ (w) (Law. Co-op. Supp. 1993), hospitals and nursing homes must inform their patients whether their states allow the cessation of treatment should they 
When Americans think of informed consent, however, they probably think of consent to risks of personal injury from medical treatment and from exposure to dangerous products. In these contexts, informed consent does not simply pursue the contract law goals of individual autonomy, efficiency, and anti-statism; it also advances two related ideas, fault and duty, that pervade and moralize tort law. These ideas, which took root and flourished during the heyday of traditional liberalism in the nineteenth century, ${ }^{12}$ hold that as long as one who suffers harm consents (in some legally meaningful sense) to bear the risk that leads to it, the injurer is not under a duty to protect the victim and is not at fault if an injury occurs. ${ }^{13}$ By relieving the injurer of a duty to the victim and negating the injurer's fault-in effect, replacing the negligence standard of care applicable to the injurer's actions with a new, less demanding standard-informed consent absolves her of tort liability. ${ }^{14}$ Informed consent claims arise at the private law intersection of torts and contracts, the laws which govern most workaday activities and choices. It is here that the social meaning of consent becomes most evident.

The doctrine of informed consent in health care ${ }^{15}$ shared in the more general expansion of American tort liability that proceeded well into the 1980's and that now appears to have stabilized. ${ }^{16}$ Everyone, it seems, favors the

become incapacitated. Care centers must provide written information regarding patient rights, living wills, and proxy decisionmaking authorized by state law. The law covers all centers that receive funding under Medicare or Medicaid. Leonard Sloane, '91 Law Says Failing Patients Must Be Told of Their Options, N.Y. TMMS, Dec. 8, 1990, at 50.

Federal law also requires all states to adopt the Center for Disease Control guidelines (or their equivalent) regarding transmission of HIV during invasive medical procedures. Under these guidelines, physicians who are HIV+ must consult expert review panels before performing surgery, and those panels may mandate disclosure to patients. Pub. L. No. 102-141, § 633, 105 Stat. 834, 876-77 (1991). See generally Jeffrey W. Cavender, Note, AIDS in the Health Care Setting: The Congressional Response to the Kimberly Bergalis Case, 26 GA. L. REV. 539 (1992). Some states have also enacted mandatory disclosure measures. See, e.g., Mark D. Johnson, Comment, HIV Testing of Health Care Workers: Conflict Between the Common Law and the Centers for Disease Control, 42 AM. U. L. REV. 479, 533-35 (1993).

11. For example, informed consent principles are resurging in the environmental context in the form of such programs as the Toxic Release Inventory and a labelling requirement on international transport of hazardous waste, see ROBERT V. PERCIVAL ET AL., ENVIRONMENTAL REGULATION: LAW, SCIENCE, AND POLICY 1203-04 (1992), as well as in an emphasis on consumer product labelling. Id. at 121-22, 131-32.

12. Compare MORTON HORWIT, THE TRANSFORMATION OF AMERICAN LAW 1780-1860 (1977) with Gary T. Schwartz, Tort Law and the Economy in Nineteenth-Century America: A Reinterpretation, 90 YALE L.J. 1717 (1981) [hereinafter Gary Schwartz, Tort Law and the Economy]. Although Schwartz finds the law of this period more hospitable to liability than Horwitz does, he does not dispute the claim that fault and duty were important limitations on liability.

13. See W. Page Keeton et al., Prosser and Keeton on the Law of Torts $\$ \S 18,68$ (5th ed. 1984) [hereinafter PROSSER \& KEETON].

14. The relationship between the concepts of duty and fault is clearer at the conceptual level than at the operational level. The operational confusion is evidenced by the difficulty of "merging" all or part of the assumed risk defense into a comparative fault regime. See infra notes $46-48$ and accompanying text.

15. This Article is concerned with informed consent in treatment decisions, not in clinical research settings. For a general discussion of the latter, see RoberT J. LEVINE, ETHICS AND REGULATION OF CLINICAL RESEARCH (2d ed. 1986); Robert J. Levine, Informed Consent in Research and Practice: Similarities and Differences, 143 ARCHIVES INTERNAL MED. 1229 (1983).

16. This expansion was most apparent in products liability, see, e.g., George L. Priest, The Current Insurance Crisis and Modern Tort Law, 96 YALE L.J. 1521 (1987) [hereinafter Priest, Current Insurance Crisis], but it was not confined to that area, see Gary T. Schwartz, The Vitality of Negligence and the 
principle of informed consent; it is "only" the specific details and applications of the doctrine that arouse serious debate. In order to map and enlarge this debate, it is useful to distinguish three different versions of informed consent doctrine. The first is the letter and spirit of the doctrine as developed primarily by courts-the law "in books." The second is the doctrine as imagined, feared, and often caricatured by some physicians-the law "in the mind." The third version, a consequence both of the gap between the first two and of other situational constraints, is the doctrine as actually practiced by clinicians-the law "in action." are distinct physician-patient relationships.)

Most commentators on informed consent deploy one or more of these versions of the law. Generally (and crudely) speaking, these commentators fall into two camps: idealists and realists. Informed consent idealists-primarily some judges and medical ethicists-advocate a relatively expansive conception of the physician's obligation to disclose and elicit information about risks and alternatives. ${ }^{18}$ More specifically, the idealists tend to define informed consent law's pivotal concepts-materiality of risk, disclosure, alternatives, and causation-broadly and subjectively from the perspective of the individual patient rather than that of the professional, while defining the law's exceptions to the duty narrowly. ${ }^{19}$ Perhaps most important, idealists emphasize the qualitative dimension of physician-patient interactions concerning treatment decisions. They insist that these interactions be dialogic rather than authoritative, tailored to the individual patient's emotional needs and cognitive capacities rather than formulaic, aimed at maximizing patient autonomy and comprehension rather than mere information flow, and sensitive to the distortions that can be created by power differentials between physician and patient.

The idealists employ a distinctive rhetorical strategy. Capitalizing on the universal support for the principles and goals of informed consent, they point to the often striking difference between the law in books and the law in action-a difference that I call the "informed consent gap." The existence of this gap, they argue, shows that the law in action falls far short of the law in

Ethics of Strict Liability, 15 GA. L. REV. 963 (1981). The pattern of stabilization is discussed in Gary T. Schwartz, The Beginning and the Possible End of the Rise of Modern American Tort Law, 26 GA. L. REV. 601 (1992) [hereinafter Gary Schwart2, The Beginning and the Possible End]; see also James A. Henderson, Jr. \& Theodore Eisenberg, The Quiet Revolution in Products Liability: An Empirical Study of Legal Change, 37 UCLA L. Rev. 479 (1990) [hereinafter Henderson \& Eisenberg, The Quiet Revolution] and Theodore Eisenberg \& James A. Henderson, Jr., Inside the Quiet Revolution in Products Liability, 39 UCLA L. REv. 735 (1992) [hereinafter Eisenberg \& Henderson, Inside the Quiet Revolution].

17. Roscoe Pound first drew the distinction between the law in action and the law in books. Roscoe Pound, Law in Books and Law in Action, 44 AM. L. REV. 12 (1910).

18. See, e.g., Canterbury v. Spence, 464 F.2d 772, 787 (D.C. Cir. 1972) (principle of informed consent requires that physician disclose information that reasonable patient would wish to know in making treatment decisions); Truman v. Thomas, 611 P.2d 902, 906-07 (Cal. 1980) (patient must be apprised of risks of not undergoing treatment, even if she has refused treatment); see also KATZ, supra note 1, at 48-84.

19. The law of informed consent is summarized infra notes 72-79 and accompanying text. 
books. Since the law that they think should be in the books is often even more demanding, the true gap is wider still. The problem, then, is not so much the law in books, which tends to demand too little of physicians; rather, it is the laws in action and in the mind. For the idealist, therefore, the goal of reform must be to close the informed consent gap by conforming the law in action, at the very least, to the law now in books.

The realists-primarily practicing physicians-harbor a different vision of informed consent. ${ }^{20}$ Although they emphatically do not contest the principle and goals of informed consent, they do question whether most patients really desire the kind of dialogue that the idealists propose. They also question whether, whatever patients desire, the gains in patient autonomy and improved outcomes produced by the dialogue are worth the additional time, money, and needless patient anxiety and confusion that informed consent may entail. Like the idealists, many realists employ a characteristic rhetoric. Rather than master the doctrinal details of the informed consent law in books, they point instead to the law in their minds, which they can easily caricature in order to demonstrate the law's folly. Although some realists do not concede that the law in action actually deviates from the law in their minds, many others readily admit that a gap does in fact exist. To them, however, this gap simply demonstrates how impractical the idealists' vision is and why it cannot be implemented in the demanding world of contemporary clinical practice. ${ }^{21}$

In a real sense, then, informed consent idealists and realists argue past one another, producing a debate that is oblique and inconclusive rather than pointed and fruitful. For several related reasons, it is time to revisit this debate. These reasons include the intense public concern about rising health care costs, the bureaucratization of the physician-patient relationship, and the organization of health care delivery into units with some degree of market power over providers. Is the informed consent gap to be deplored or tolerated? Should physicians' legal obligations to disclose be further expanded, retained in their present form, or reduced? I approach these questions in part by asking what can be learned by comparing informed consent doctrine in other areas of personal injury law, especially products liability, with the doctrine applicable to the health care setting ("informed consent proper"). I ask how costeffective $^{22}$ informed consent doctrine is in practice, and in that connection, I ask whether it is as sensitive as it should be to the different clinical contexts

20. Perhaps the most articulate of the realists is Dr. Thomas P. Duffy. See Thomas P. Duffy, Agamemnon's Fate and the Medical Profession, 9 W. NEW ENG. L. REV. 21 (1987) (reviewing and criticizing Jay Katz's approach). Dr. Sherwin Nuland advances a more moderate realist position in his forthcoming book. See SHERWIN B. NULAND, HOW WE DIE: REFLECTIONS ON LIFE's FINAL CHAPTER 25861, 265-67 (forthcoming 1994) (distinguishing, inter alia, between family physicians, who can and should engage in meaningful informed consent dialogue with patients, and specialists, who cannot realistically be expected to do so).

21. NULAND, supra note 20, at 258-61, 265-67; Duffy; supra note 20, at 24.

22. See infra note 23 . 
in which it arises. The answers to such questions, I hope, will refocus the debate and enable us to reconsider the utility of the doctrine in its present form.

I conclude that the problem of the informed consent gap is essentially structural-that is, it reflects the constraints imposed by human psychology, the physician-patient relationship, the tort law system, and an increasingly costconscious health care delivery system-and that these constraints are largely intractable. I therefore doubt that the idealists' most ambitious goals are desirable, since they cannot likely be attained at any socially acceptable cost. I am doubtful because, although I find reasons to think that the idealists are wrong, I am not yet as convinced of their error as some realists appear to be. The truth is that no one has yet undertaken the kind of research and analysis, much of it empirical and perhaps comparative, that would be necessary to resolve these doubts conclusively. By explaining the basis for these concerns, proposing how this analytical challenge might be approached, and suggesting certain improvements that can probably be made at a modest cost, I hope to help close the informed consent gap.

Part II places the legal idea of consent in historical and doctrinal context, discussing its role in tort law generally, and in two subfields of tort law: products liability and informed consent proper (i.e., in health care). The discussion concerns the law in books.

Part III is comparative in nature. It focuses on the similarities and differences between informed consent proper and its analogues in products liability law and tort law more generally. It argues that the doctrine of informed consent proper is in most respects more onerous to risk creators than in these other areas. I then consider five plausible arguments that might justify the different burdens that the law imposes on potential tortfeasors to engage in a dialogue with foreseeable victims. These arguments proceed from claims about autonomy, relational continuity, conflict of interest, inequality of information and bargaining power, and, finally, utility. Scrutinizing these five arguments from this comparative perspective, I conclude that none of them satisfactorily explains the disparity in dialogic burden, although the argument from information inequality probably comes closest.

Part IV begins by emphasizing the growing public demand for health care cost containment, noting that these pressures underscore the importance of reassessing the appropriate contours of informed consent. This reconsideration, I suggest, should proceed along four different paths.

First, informed consent doctrine should be subjected to an analysis of its cost-effectiveness $^{23}$ that is as systematic as this elusive, value-laden subject

23. For policies like informed consent whose benefits are especially difficult to measure and compare to costs, cost-effectiveness is often a more useful decision-making criterion than cost-benefit analysis. See EDITH STOKEY \& RICHARD ZECKHAUSER, A PRIMER FOR POLICY ANALYSIS 153-55 (1978). 
permits. A cost-effectiveness analysis accepts the undeniably attractive goals of informed consent law in books (as I and virtually all other commentators on the subject do) and asks whether they can be achieved more fully, more cheaply, or both. It focuses attention on the costs and benefits of the far different and rather less inspiring regime of informed consent in action, on other possible regimes, and hence on the changes in clinical practice that must occur if the goals of the law in books are to be achieved.

Second, providers should alter the way in which they characterize and communicate treatment (and nontreatment) risks to patients so that the information will be more meaningful, accurate, and useful. Specifically, I urge that physicians begin to describe risks in comparative terms so that patients can view these risks in light of other, more familiar ones that they face in daily life. Only then can they appraise these risks in a sophisticated, autonomyenhancing way.

A third path emphasizes the contingency and contextuality of perception and meaning. ${ }^{24}$ The significance of consent to an individual, and to the society that must decide whether to give effect to it, depends on the circumstances in which it is elicited. Much the same can be said of people's perceptions and attitudes about risk. This fact has important implications for assessing what is now a quite monolithic informed consent doctrine in health care. If that doctrine is to become more sensitive to the various contexts in which it is applied, it must become more highly differentiated, ${ }^{25}$ which would in turn make the doctrine more refined and presumably more cost-effective.

Finally, the law should foster this kind of differentiation by facilitating and enforcing explicit contracts between providers and patient groups about the desired characteristics of informed consent. A contract strategy is already practicable in some settings and will become more universally so as national health reforms organize patients into larger, more sophisticated, and more consumer-oriented health care purchasing units-a prospect that in broad terms seems inevitable.

All of these goals share a common theme: the need to contextualize informed consent. Contextualization would advance the aim of costeffectiveness and would also be desirable in its own right. Each goal seeks to improve the informed consent dialogue, and the doctrine that regulates it, by tailoring the law's requirements more carefully to the different settings in which risks arise and are discussed, assessed, and acted upon.

24. This notion is well established in the psychology literature. See, e.g., JUDGMENT UNDER UNCERTAINTY: HEURISTICS AND BIASES (Daniel Kahneman et al. eds., 1982) [hereinafter JUDGMENT UNDER UNCERTAINTY].

25. The optimal level of differentiation that a legal dostrine should seek is a separate question. See infra note 216 and accompanying text. 


\section{CONSENT IN CONTEMPORARY TORT LAW}

\section{A. Historical Context}

Few legal ideas are more sensitive to evolving social conditions and values than consent. According to legal historian Morton Horwitz, private law's view of consent has changed radically as new economic and social conditions have altered power relationships and reshaped legal doctrine. ${ }^{26}$ While some scholars dispute Horwitz's claim that the scope of consent-based defenses expanded greatly during the nineteenth century, ${ }^{27}$ most would agree that the courts have narrowed these defenses in recent decades, a trend that has contributed to the general growth of liability (especially tort liability) during this period. Torts scholars have found that courts became increasingly reluctant to dismiss personal injury claims on the ground that the victims consented to the injury-causing risks; in particular, the courts strongly disfavored consentbased defenses such as assumption of the risk and product warning. ${ }^{28}$ The. reasons for this trend are uncertain. Some scholars have attributed it to the courts' desire to use expansive tort liability as a system of risk distribution and insurance. ${ }^{29}$ Others have pointed to a more general anti-market public policy mentality that prevailed during the 1960's and early 1970's, when much of this liability expansion occurred. ${ }^{30}$

Two developments have rendered somewhat paradoxical this expansion of tort law and its intrusion into contract law, the realm of mutual consent. First,

26. In its most general terms, Horwitz's thesis holds that prior to the middle of the 19th century, state courts developed a number of doctrines that in effect relieved individuals of the adverse consequences of choices for which the courts felt they should not in fairness be held responsible. In contract law, the courts fashioned liberal defenses of duress, unconscionability, incompetence, and others designed to protect individuals whom the courts thought were in relatively weak bargaining positions; their formal consent was deemed uninformed, involuntary, or otherwise unauthentic. With industrialization, however, the courts sought to protect capitalist enterprise from the uncertainties and burdens imposed by these doctrines by adopting a more formalistic, laissez-faire, objectivist view of consent. Horwitz discerns a similar pattern in tort Jaw, where courts that had previously protected personal injury victims through narrow interpretations of the traditional consent-based defenses to liability began during the Industrial Revolution to broaden these defenses with the goal of subsidizing risky enterprises. HORWITZ, supra note 12, at 20110, 253; HORWIT, THE TRANSFORMATION OF AMERICAN LAW 1870-1960, at 13-14 (1992).

27. Horwitz's view has been severely criticized on the contracts side, A.W.B. Simpson, The Horwitz Thesis and the History of Contracts, 46 U. CHI. L. REv. 533, 542 (1979) ("[T] he changes [Horwitz] describes were not the changes that occurred.... [M] any of the doctrines that he identifies as characteristic of the transformation were common in the eighteenth century."), and on the torts side, Gary Schwartz, Tort Law and the Economy, supra note 12, at 1772-73. Schwartz notes that the assumed risk defense in the employment context was an exception to "the general tendency toward victim protectiveness." Id. at 1771.

28. PROSSER \& KEETON, supra note 13, at 493-94. According to a leading historian of tort law, this defense "seemed just about extinct" by 1980. Gary Schwartz, The Beginning and the Possible End, supra note 16 , at 671 .

29. See, e.g., Peter Huber, LiabiltTy: The Legal Revolution and ITS CONSEQuences (1988); Priest, Current Insurance Crisis, supra note 16, at 1524-25.

30. See, e.g., Peter H. Schuck, The New Judicial Ideology of Tort Law, in NEW DIRECTIONS IN LIABILITY LAW 4, 6-8 (Walter Olson ed., 1988) [hereinafter NEW DIRECTIONS]; Gary Schwartz, The Beginning and the Possible End, supra note 16, at 615-20. 
the rise of one kind of contract, third-party ("liability") insurance, helped to facilitate the "death of contract" in other areas of the law." Liability insurance, by encouraging courts concerned with risk spreading to develop doctrines conducive to that goal, enabled tort plaintiffs to reach the "deep pockets"-insurers, the ultimate risk spreaders-more easily. Moreover, this liability-expanding effect of insurance occurred during a period when private and social insurance coverage for illness, disability, and wage loss, which might have been expected to reduce the scope and significance of tort liability, was also growing dramatically. ${ }^{32}$

The second paradoxical development is tort law's displacement of contract in areas of commercial activity in which explicit contracts already exist and contract principles have traditionally governed legal relationships almost exclusively. These are also areas in which the argument that insurance considerations should affect liability is often especially weak-because, for example, both parties are good loss-spreaders. Indeed, tort law's most striking growth has been in products liability, an area in which plaintiffs and defendants interact as arm's-length buyers and sellers in an explicitly commercial context that provides a full set of well-developed contract remedies. A less dramatic development, but one more pertinent to this Article, is tort law's expansion in the health care setting (as in medical malpractice and informed consent law) at the very same time that important changes in the nature and institutional setting of the provider-patient relationship were making contract more suitable than tort as a legal regime for regulating those relationships. ${ }^{33}$

Tort law has largely eclipsed consent-contract approaches to the problem of health-care-related injuries. No-fault compensation systems, which might have slowed this development by displacing tort law to some extent, have instead found little political support in the United States. The movement toward mandatory no-fault compensation systems, which began with workers' compensation almost a century ago and once seemed like the wave of the future, ${ }^{34}$ stalled during the 1970's and has hardly progressed since then. ${ }^{35}$

31. GRANT GILMORE, THE DEATH OF CONTRACT $87-94$ (1974) (describing growing use of tort-like doctrines, such as promissory estoppel, to expand liability beyond scope of traditional contract law).

32. For the growth of first-party insurance and its overlap with tort liability, see Jeffrey O'Connell, Must Health and Disability Insurance Subsidize Wasteful Injury Suits?, 41 RUTGERS L. REV. 1055, 1059-61 (1989); see also DEBORAH HENSLER ET AL., COMPENSATION FOR ACCIDENTAL INJURIES IN THE UNITED STATES 102-08 (1991).

33. See infra note 125 and accompanying text.

34. See Jeremiah Smith, Sequel to Workmen's Compensation Acts, 27 HARV. L. REv. 344, 365 (1914) ("Whether [no fault] legislation of the above descriptions ought to be enacted is a question upon which no opinion is here intimated. Our immediate point is, that the present Workmen's Compensation legislation will inevitably give rise to a plausible agitation for such further legislation.").

35. In the most important area of accidents, motor vehicle injuries, federal no-fault legislation was decisively defeated during the 1970's. Robert L. Rabin, Some Reflections on the Process of Tort Reform, 25 SAN DIEGo L. REv. 13, 19-22 (1988). Moreover, almost all of the state programs that exist are essentially "add-ons" to the tort system rather than genuine no-fault plans. See, e.g., Roger S. Clark \& 
In addition, contractual no-fault plans in which individuals agree in advance with risk creators to waive or limit their tort claims in return for an assured no-fault recovery in the event of injury have not been widely adopted ${ }^{36}$ As for contractual no-fault, courts have been inhospitable to waivers of potential tort claims, often refusing to enforce them. This has been especially true in the area of health care. ${ }^{37}$

During the 1980's, however, proponents of consent-contract approaches to personal injuries launched a strong counterattack. In books, articles, and legislative proposals, consent-contract advocates drew on theoretical arguments grounded in law-and-economics principles, and on policy arguments grounded in the high transaction costs and perverse consequences of the tort system. These reformers urged legislatures and courts, among other things, to reinvigorate the assumed risk and product warning defenses, and to enforce informed, consensual risk allocations designed to contract around the tort system..$^{38}$ As the next Section demonstrates, their efforts have not yet enjoyed much success.

\section{B. Doctrinal Context}

I shall discuss three major doctrinal domains of American personal injury law in which the idea of informed consent is embedded. ${ }^{39}$ They are (1) tort

Gerald E. Waterson, "No-Fault" in Delaware, 6 RUT.-CAM. L.J. 225 (1974) (discussing Delaware's add-on plan). In the area of medical malpractice, mandatory no-fault has received little serious legislative consideration. For a summary of recent developments, see MARC A. FRANKLIN \& ROBERT L. RABIN, CASES AND MATERIALS ON TORT LAW AND ALTERNATIVES 783-87 (5th ed. 1992). The trial bar has played an important role in the defeat of no-fault legislation. See, e.g., JEFFREY O'CONNELL \& C. BRIAN KEl.LY, THE BLAME GAME: INJURIES, INSURANCE, AND INJUSTICE 117-18 (1987); Jeffrey O'Connell et al., Consumer Choice in the Auto Insurance Market, $52 \mathrm{MD}$. L. Rev. (forthcoming 1994); W. John Moore, Trial Lawyers on Trial, 22 NAT'L. J. 2962 (1990).

36. These are sometimes called "neo-no-fault" by their principal advocate, Jeffrey O'Connell, who has designed many such systems to cover accidents in a wide variety of settings such as health care delivery, school athletics, product injuries, and governmentally caused injuries. See, e.g., Jeffrey O'Connell, Neo-NoFault: A Fair-Exchange Proposal for Tort Reform, in NEW DIRECTIONS, supra note 30, at 186 [hereinafter O'Connell, Neo-No-Fault]; see also Jeffrey O'Connell, A "Neo No-Fault" Contract in Lieu of Tort: PreAccident Guarantees of Postaccident Settlement Offers, 73 CAL. L. REv. 898 (1985) (discussing forums which have adopted "neo-no-fault" programs and how such programs have been received).

37. See infra notes $43-44$ and accompanying text.

38. RICHARD EPSTEIN, MODERN PRODUCT LIABILITY LAW 147-51 (1980) (proposing enforcement of consensual liability limits in certain well-defined circumstances); Alan Schwartz et al., Encouraging Contractual Altematives to Tort, in 2 AMERICAN LAW INSTITUTE, COMPENSATION AND LIABILITY FOR PRODUCT RELATED INJURIES: PROPOSED FINAL REPORT, COUNCIL DRAFT \# 1, at 581 (1990) [hereinafter Alan Schwartz, Encouraging Alternatives] (same); O'Connell, Neo-No-Fault, supra note 36 (same). In 1985, Senators John Danforth and David Durenberger submitted legislation based on O'Connell's scheme to reform the medical malpractice tort system. 131 CONG. REC. 36,870 (1985). Their proposal was not enacted. See also PAUL H. RUBIN, TORT REFORM BY CONTRACT (1993); HUBER, supra note 29, at 220-24 (criticizing courts' rejection of consent-based defenses to tort liability); George L. Priest, $A$ Theory of the Consumer Product Warranty, 90 YALE L.J. 1297, 1347-49 (1981) (criticizing courts' rewriting of product warranties) [hereinafter Priest, Consumer Product Warranty].

39. Other areas not discussed here include the settlement of tort claims, see, e.g., Hume v. MooreMcCormack Lines, Inc., 121 F.2d 336 (2d Cir.), cert. denied, 314 U.S. 684 (1941) (release of tort claims signed by seaman not valid with respect to disease of which he was unaware at the time), and workers' 
law generally, which introduces informed consent through the assumed risk defense; (2) products liability law, which introduces it through the concept of warning defect; and (3) what I have called informed consent proper, the doctrine as applied to the health care treatment setting. I shall briefly discuss the first two here; the third is the subject of Part II. This doctrinal review reveals that a health care provider's obligations toward patients are in several respects more onerous than those that other actors owe to potential victims and those that product manufacturers and sellers owe to their purchasers and consumers. The comparative analysis that follows in Part II calls into question, although it does not flatly reject, the justification for imposing this greater burden on health care providers.

\section{Tort Law Generally}

In tort law, the risk assumptions that may defeat a victim's liability claim can be either express or implied. In express assumption of risk situations, the victim has, prior to the accident, expressly agreed to release a potential injurer from tort liability for specified (or all) injuries that the victim might sustain in connection with certain activities. The agreement can take the form of a signed, highly explicit waiver of possible tort claims contained in a written contract, as when one rents skis or a whitewater canoe. At the other end of the explicitness spectrum, the agreement can take the form of a printed waiver that appears in small print on the back of a ticket stub issued by a parking lot or movie theater. ${ }^{40}$ Legislatures often prohibit and courts often invalidate the latter kind of agreement as a matter of public policy. Stigmatizing this type of waiver as a contract of adhesion, they emphasize the consumer's lack of bargaining power, alternatives, risk information, and awareness of the waiver-in essence, her lack of informed consent to the risk. ${ }^{41}$

compensation law, which excludes claims deriving from conduct that is either, depending on the jurisdiction's statute, intentional or reckless, see generally ARTHUR LARSON, WORKERS' COMPENSATION LAW: CASES, MATERIALS AND TEXT 449-88 (1984). By stretching the notion of worker consent, one can think of these categories as tantamount to a recognition that the worker can consent to her own injury. Analogous defenses usually exist in other no-fault systems. See, e.g., N.Y. INS. LAW \& 5103(b) (McKinney 1985) (automobile no-fault).

40. Compare Garretson v. United States, 456 F.2d 1017 (9th Cir. 1972) (barring claim of experienced skier who signed entry blank for ski tournament containing conspicuous release) with Baker v. City of Seattle, 484 P.2d 405 (Wash. 1971) (en banc) (voiding as contrary to public policy one-sentence exculpatory clause buried in midst of other terms of golf-cart rental agreement).

41. See, e.g., Wagenblast v. Odessa Sch. Dist. No. 105-157-166J, 758 P.2d 968, 971 (Wash. 1988) (using six factors named in Tunkl v. Regents of University of California, 383 P.2d 441 (CaI. 1963), to invalidate requirement that students wishing to participate in interscholastic sports had to waive negligence claims against school district); Henrioulle v. Marin Ventures, Inc., 573 P.2d 465 (Cal. 1978) (invalidating lease that included general release of owner from negligence actions). For examples of state legislation, see N.Y. GEN. OBLIG. LAW $\$ \$ 5-321$ to 5-326 (Consol. 1977). For an example of federal legislation providing for special scrutiny of waivers of certain liability claims, see Older Workers Benefit Protection Act, 29 U.S.C.S. § 626(f) (Law. Co-op. Supp. 1993). 
Of greater interest here, however, is the tendency of courts to override explicit waivers even when the consumer's attention is called to the risk and she makes a conscious choice to accept the risk with some knowledge of the danger. This tendency is especially pronounced in the health care treatment setting, where courts have made it almost impossible to design enforceable risk-sharing agreements between consumers and providers. ${ }^{42}$

In this genre, the leading case is Tunkl v. Regents of University of California ${ }^{43}$ In Tunkl, the California Supreme Court invalidated a waiver clause in a hospital admission form. The court emphasized six factors justifying its action: (1) health care is a business "generally thought suitable for public regulation"; (2) the hospital was performing a service necessary to the public; (3) the hospital held itself out as willing to perform this service for any member of the public; (4) the hospital had greater bargaining strength than the consumer; (5) the waiver form was an adhesion contract which did not permit consumers to purchase more protection if they chose; and (6) the hospital controlled the risk of injury and could be negligent. The Tunkl approach of examining the circumstances surrounding execution of the waiver and construing it very narrowly has been extended to other health care settings. In a recent New York case, for example, the court invalidated an agreement by a dental patient to waive tort claims in exchange for receiving care from supervised graduate students at a university clinic. His private dentist had urged him to contact the clinic, which agreed to perform the needed service for less than half the ordinary fee. ${ }^{44}$

Assumption of risk may also be implied. Here, one's alleged consent is not expressed through execution of a signed document or acceptance of a receipt reciting the consent as a condition of service; instead, defendants argue that consent is implicit in the relationship between the parties and in the plaintiff's behavior and understandings. The common law of industrial accidents, before it was supplanted by workers' compensation statutes, provides the classic example of implied assumption of risk. ${ }^{45}$

Today, however, most courts and legislatures evince considerable hostility to the defense of implied assumption of risk. The dominant approach has been

42. These court decisions did not involve informed consent proper. See generally Clark C. Havighurst, Private Reform of Tort-Law Dogma: Market Opportunities and Legal Obstacles, LAW \& CONTEMP. PROBS., Spring 1986, at 143 (discussing courts' reluctance to uphold exculpatory clauses for medical malpractice and pointing to some reform possibilities).

43. 383 P.2d 441 (Cal. 1963). See generally ClaRk C. Havighurst, Health CARE LAW AND POLICY 903-04 (1988) (discussing cases where such agreements have been invalidated).

44. Ash v. New York Univ. Dental Ctr., 564 N.Y.S.2d 308 (App. Div. 1990); see also Emory Univ. v. Porubiansky, 282 S.E.2d 903 (Ga. 1981) (holding that exculpatory clause in contract did not relieve dental clinic of duty of reasonable care). In a recent case not involving a health care provider, the Supreme Court of Washington invalidated an agreement in which parents of schoolchildren waived liability claims against the school for injuries from after-school sports activities, even though the decision might result in the elimination of the sports program. Wagenblast, 758 P.2d at 968.

45. See generally JOSEPH W. LITTLE ET AL., CASES AND MATERIALS ON WORKERS' COMPENSATION 16-17 (3d ed. 1993). 
to eliminate or narrow the defense, thereby facilitating plaintiffs' recoveries. ${ }^{46}$ This narrowing is usually accomplished by "merging" the implied assumption of risk doctrine, in whole or in part, ${ }^{47}$ into comparative fault, a doctrine that has itself been broadened from the traditional contributory negligence concept in order to increase recoveries. ${ }^{48}$ Because a plaintiff's comparative fault merely reduces her recovery pro tanto while assumed risk is ordinarily a complete defense, this merger does not fully immunize defendants from liability for risks to which the victim in fact consented. Hence, the merger of assumed risk into comparative fault renders informed consent somewhat less effective, but not wholly irrelevant.

In the United States, an important institutional feature of implied assumption of risk is that courts consider the defense to be an issue of fact for the jury to decide. Precisely because it is a jury question, the application of the implied assumption of risk doctrine is shaped by evolving social norms concerning fundamental issues of morality: the meaning of fairness, reciprocity in relationships, the extent of free will, individual responsibility for choice, and the like. It is in this sense that implied assumption of risk, notwithstanding its ostensible and legally institutionalized character as a "fact," is in reality a culturally constructed and highly normative doctrine, one that is highly responsive to changing social values.

Recent judicial decisions underscore the plasticity of the assumed risk doctrine-and, thus, that of the underlying informed consent principle. Decisions by the Supreme Court of California in particular could portend a reversal of the strong judicial trend of narrowing the ambit of the assumed risk doctrine. ${ }^{49}$ A number of recent decisions in California and elsewhere have allowed the assumption of risk defense in cases of recreational injuries. ${ }^{50}$ This apparent revival of interest in informed consent as a limitation on liability has

46. PROSSER \& KeETON, supra note 13 , at 493-95.

47. Sometimes the merger is complete and assumption of risk is wholly eliminated as a defense. In other situations, however, only "unreasonable" assumptions of risk are merged into comparative fault, in which case "reasonable" assumption of risk remains as a defense independent of comparative fault. See id. at $495-98$.

48. Id.

49. Of course, it is still too early to tell. See Gail D. Cox, Assumption of Risks, NAT'L L.J., Oct. 28, 1991, at 1, 24-25. The meaning of consent in other contexts, such as rape cases, is also highly controversial. See, e.g., Stephen J. Schulhofer, Taking Sexual Autonomy Seriously: Rape Law and Beyond, 11 LAW \& PHIL. 35, 76-77 (1992) (arguing that consent requires clear expression of positive willingness); Steven B. Katz, Expectation and Desire in the Law of Forcible Rape, 26 SAN DIEGo L. REV. 21, 21 (1989) (noting that law constructs and assumes women's consent); Lucy R. Harris, Comment, Towards a Consent Standard in the Law of Rape, 43 U. CHI. L. REV. 613, 613-14 (1976) (arguing that consent in rape law should conform to consent in other legal areas). For a related critique of the notion of consent, see Robin West, Authority, Autonomy \& Choice: The Role of Consent in the Moral and Political Visions of Franz Kafka \& Richard Posner, 99 HARV. L. REV. 384 (1985).

50. See, e.g., Knight v. Jewett, 834 P.2d 696 (Cal. 1992) (using assumption of risk doctrine to bar claim of player injured in touch football game); Turcotte v. Fell, 502 N.E.2d 964 (N.Y. 1986) (using assumption of risk doctrine to bar jockey's suit against racetrack owner); see also FowLER V. HARPER ET AL., THE LAW OF TORTS $\$ 21.0$ n.16 (2d ed. 1986 \& Supp. 1993); Gary Schwartz, The Beginning and the Possible End, supra note 16, at $672 \mathrm{nn} .377-80$. 
not yet been applied to injuries incurred at the hands of health care providers, but it could spread to them.

In light of the discussions of products liability and informed consent proper that follow, one other feature of the assumed risk doctrine should be emphasized. In contrast to product suppliers and health care providers (informed consent proper), actors who are governed by tort law are generally under no statutorily or judicially imposed obligation to warn their potential victims about, much less affirmatively obtain their consent to, risks of injury. In order to relieve the injurer of liability, it is enough that the victim encountered the risk with the requisite knowledge and voluntariness. Indeed, actors governed by tort law generally need not communicate about the risk at all; the defense will still apply so long as the victim consents, in this sense, to encounter it.

\section{Products Liability}

The law of sales traditionally governed the liability of product distributors for product-related injuries; products liability in tort was historically a backwater, generating relatively few cases, slow doctrinal change, and little public attention. ${ }^{51}$ This situation changed beginning in California in the early 1960 's. ${ }^{52}$ Doctrinal innovation in the area spread to other states in succeeding decades, ${ }^{53}$ as strict liability for defective products became the regnant doctrine, eclipsing sales law and negligence as the remedies of choice for injured consumers. ${ }^{54}$ The expansion of products liability doctrine was dramatic, continuing well into the 1980's, when (according to some recent analyses) it began to contract ${ }^{55}$ or at least stabilize. ${ }^{56}$

Informed consent is a crucial limitation on products liability. Here it is imbedded in the warning defect doctrine; if the product fails adequately to warn the purchaser (or ultimate consumer) about the product's risks, courts deem the product to be "defective" and hold the distributor liable for injuries

51. See, e.g., George L. Priest, Strict Products Liability: The Original Intent, 10 CARDozo L. Rev. 2301, 2305-17 (1989).

52. The seminal cases were Greenman v. Yuba Power Products, Inc., 377 P.2d 897 (Cal. 1963) (establishing strict liability for manufacturers of defective products), Vandermark v. Ford Motor Co., 391 P.2d 168 (Cal. 1964) (establishing strict liability for distributors of defective products), and Elmore v. American Motors Corp., 451 P.2d 84 (Cal. 1969) (holding that bystanders can recover for injury caused by product defect under strict liability theory).

53. These developments are summarized in Gary T. Schwartz, Directions in Contemporary Products Liability Scholarship, 14 J. LEGAL STUD. 763 (1985).

54. See generally George L. Priest, The Invention of Enterprise Liability: A Critical History of the Intellectual Foundations of Modern Tort Law, 14 J. LEGAL STUD. 461 (1985). Priest's premise of "near absolute" corporate liability is explicitly rejected by Gary Schwartz, who finds that negligence remains the standard of liability in many important areas of tort law and that even strict liability for defective products is not as strict as Priest's work sometimes suggests. Gary Schwartz, The Beginning and the Possible End, supra note 16 , at $621-33$.

55. Henderson \& Eisenberg, The Quiet Revolution, supra note 16, at 489-98.

56. Gary Schwartz, The Beginning and the Possible End, supra note 16, at 603. 
caused by those risks. In effect, an adequate warning conclusively establishes that the plaintiff assumed the risk. As a practical matter, even product labels that contain a great deal of pertinent risk information-indeed, more than most consumers are likely to read or assimilate-can easily fail the negligence standard by which a court and jury measure the warning's adequacy. To courts and juries, the cost of supplying additional label information appears negligible, amounting to the cost of ink and paper, while the cost of injuries that the information might avert is significant. An alternate possibility-that more information may actually produce less comprehension, perhaps even leading to more injuries-is more subtle and difficult to prove. Under these circumstances, it is not surprising that product warning requirements became more onerous. ${ }^{57}$

Some courts and juries have demanded much more than mere "reasonable" warnings. Some notorious decisions illustrate the expansiveness of many interpretations of warning defect liability. ${ }^{58}$ Courts either found or permitted juries to find warning defects in a vaccine producer's failure to warn of a onein-a-million risk of a serious side effect, ${ }^{59}$ a brewery's failure to warn that its beer was unsafe if consumed in moderate quantities (ten to twelve cans per week) for more than six years; ${ }^{60}$ a champagne bottler's failure to warn about the release of pressure when removing the cork; ${ }^{61}$ a manufacturer's failure to warn that a vehicle driven up too steep a slope could flip end-over-end; ${ }^{62}$ a warning not to use alcohol near a flame that did not warn also against use near a pilot light: ${ }^{63}$ and a warning that birth control pills could cause death through brain clotting but that failed to warn about death from stroke. ${ }^{64}$ The New Jersey Supreme Court went so far as to require that asbestos manufacturers warn of hazards that were not reasonably knowable under the existing state of knowledge and technology. ${ }^{65}$

The problem of unrealistic warning requirements is in part endemic, reflecting the kinds of product accidents that litigants bring to court. Alan Schwartz has explained this phenomenon:

57. One commentator notes that a more restrictive "counter-trend" in warning doctrine emerged during the 1980's. Id.

58. I do not suggest that these are representative of the larger universe of warning cases.

59. Reyes v. Wyeth Lab., 498 F.2d 1264 (5th Cir.), cert. denied, 419 U.S. 1096 (1974).

60. Hon v. Stroh Brewery Co., 835 F.2d 510 (3d Cir. 1987).

61. Shuput v. Heublein, Inc., 511 F.2d 1104 (10th Cir. 1975).

62. Leichtamer v. American Motors Corp., 424 N.E.2d 568 (Ohio 1981).

63. Burch v. Amsterdam Corp., 366 A.2d 1079 (D.C. App. 1976). (1985).

64. MacDonald v. Ortho Pharmaceutical Corp., 475 N.E.2d 65 (Mass.), cert. denied, 474 U.S. 920

65. Beshada v. Johns-Manville Prods. Corp., 447 A.2d 539 (N.J. 1982). Responding to a chorus of criticism, the court subsequently "restrict[ed] Beshada to the circumstances giving rise to its holding." Feldman v. Lederle Lab., 479 A.2d 374, 388 (N.J. 1984). While the scope of this restriction is not entirely clear, it presumably limits the Beshada principle to asbestos litigation. However, the court explicitly refused to overrule Beshada. Id.; cf. Anderson v. Owens-Corning Fiberglas Corp., 810 P.2d 549, 557 (Cal. 1991) (holding that plaintiffs in all failure-to-warn actions, even in asbestos cases, must show that defendant knew or should have known of the product risk). 
Initially, juries see only cases where a consumer is injured in consequence of a malfunction against which the firm failed to warn or is claimed to have warned inadequately. The jury never is told of other possible malfunctions or asked to rank these by degree of danger. Rather, the jury is asked to assess the firm's performance with respect to the malfunction that actually happened. Thus, the jury cannot know whether a firm's failure to warn was correct in light of other risks that the product posed, or whether a warning that appears too pallid ex post actually was correct because other risks were more serious. This institutional system, therefore, creates poor incentives for firms. They may respond by warning against malfunctions that have been involved in litigation because not to do so invites punitive damage claims, although these may pose the less-serious risks. Alternatively, firms may try to warn against everything. Either response reduces the efficacy of warnings against major risks: in the former case, such warnings may not be given; in the latter, these warnings may be lost in the clutter. ${ }^{66}$

Other doctrinal wrinkles have contributed to the expanded scope of warning defect liability and hence of products liability. For example, a jury can find a perfectly adequate label defective if it thinks that advertising for the product undercut the label's efficacy as a warning, ${ }^{67}$ and a jury can find defective a label that fully complied with a regulatory agency's safety labeling requirements. ${ }^{68}$ Perhaps most striking, some courts have helped plaintiffs to meet the otherwise difficult burden of proving that a warning defect was also a cause-in-fact of the injury-that is, that the injury would not have occurred had the warning been adequate. In order to facilitate this proof, these courts have adopted four presumptions: first, that the manufacturer knew all productrelated risks that could reasonably be known; ${ }^{69}$ second, that the manufacturer could warn the consumer about these risks cheaply (again, largely the cost of ink and paper); third, that consumers would actually read and comprehend an adequate warning; and fourth, that if consumers had received an adequate warning, they would have made a risk-minimizing choice-presumably without regard to possible offsetting benefits. ${ }^{70}$ Each of these presumptions is

66. Alan Schwartz, The Case Against Strict Liability, 60 FORDHAM L. REV. 819, 841 (1992). Schwartz recommends that risks be ranked across products as well as for single products, and that warnings should be measured according to the product's "global" ranking. Id.

67. See Hon v. Stroh Brewery Co., 835 F.2d 510, 514-15 (3d Cir. 1987) (recognizing that though risks of beer drinking are arguably obvious, advertising linking consumption of eight to twelve cans of beer a week with good health could nullify awareness of risks); Baldino v. Castagna, 478 A.2d 807, 810 (Pa. 1984) (holding that manufacturer's promotion of drug to physicians may nullify effect of its warnings). See generally Martha K. Wivell \& Daniel A. O'Fallon, Drug Overpromotion: When Is a Warning Not a Warning?, TRIAL, Nov. 1992, at 20 (discussing physicians' duty to warn patients of risks from prescription drugs and effects of manufacturers' sales efforts on physicians).

68. Ferebee v. Chevron Chem. Co., 736 F.2d 1529 (D.C. Cir.), cert. denied, 469 U.S. 1062 (1984).

69. Some products liability decisions demand even more from the manufacturer. See, e.g., Beshada, 447 A.2d at $546-47$ (finding product defective regardless of whether dangers were scientifically knowable).

70. See, e.g., Garside v. Osco Drug, Inc., 976 F.2d 77, 80-81 (1st Cir. 1992); Coffman v. Keene Corp., 
questionable. Several, especially the last two, are highly doubtful with respect to product purchases; as we shall see in Part II, they are demonstrably false with respect to most health care treatment decisions.

Expansive doctrines like these have aroused much criticism from legal commentators. By the mid-1980's, courts began having second thoughts about interpreting warning defect so broadly, and their rulings began to reflect these misgivings. ${ }^{71}$ Nevertheless, some of the unrealistic, perhaps perverse demands of informed consent in products liability that are implicit in the earlier product warning decisions survive relatively undisturbed in the area of health care treatment decisions, to which I now turn.

\section{Informed Consent Proper}

Physicians may not deal with their patients at arm's length; they owe their patients a fiduciary duty, which includes an obligation to act exclusively in the patient's interests and to disclose all information material to those interests. ${ }^{72}$ In slightly over half the states, the legal standard for disclosure to patients is that which a "reasonable medical practitioner" would provide. ${ }^{73}$ This professionally defined standard is often that of the locality in which the practitioner works, or a similar locality. ${ }^{74}$ The disclosure standard in most other jurisdictions is that which would be sought by a prudent or reasonable patient, a standard that emphasizes the value of patient autonomy over that of professional judgment. ${ }^{75}$

The states vary in their rules concerning what information must be disclosed. New York requires only that the practitioner provide information about reasonably foreseeable risks and alternative treatments, ${ }^{76}$ while the new

628 A.2d 710, 716-24 (N.J. 1993). But see Thomas v. Hoffmann-LaRoche, Inc., 949 F.2d 806 (5th Cir. 1992) (refusing to apply presumption for products with unavoidable risks). Indeed, some product misuse decisions, by requiring manufacturers' warnings to anticipate consumers' abnormal uses, facilitate the causal proof without the need to invoke this presumption. E.g., Ellsworth v. Sherne Lingerie, Inc., 495 A.2d 348 (Md. 1985) (ignition of nightgown worn inside out).

71. Henderson \& Eisenberg, The Quiet Revolution, supra note 16, at 488-98; Gary Schwart2, The Beginning and the Possible End, supra note 16, at 666-67.

72. See generally Maxwell J. Mehlman, Fiduciary Contracting: Limitations on Bargaining Between Patients and Health Care Providers, 51 U. PITT. L. REV. 365 (1990). For an interesting, recent application of this fiduciary duty, see Moore v. Regents of University of California, 793 P.2d 479 (Cal. 1990), cert. denied, $111 \mathrm{~S}$. Ct. 1388 (1991) (mandating disclosure of physician's research and financial interests in patient's cells).

73. BARRY R. FURROW ET AL., LIABILITY AND QUALITY ISSUES IN HEALTH CARE 337 (1991).

74. See, e.g., Chapel v. Allison, 785 P.2d 204, 210 (Mont. 1990) (holding non-board-certified general practitioner to standard of care of a reasonably competent general practitioner acting in same or similar community in United States); Henning v. Thomas, 366 S.E.2d 109, 112 (Va. 1988) (applying statewide standard of care in medical malpractice case).

75. The landmark decision was Canterbury v. Spence, 464 F.2d 772, 787 (D.C. Cir. 1972). See generally Marjorie M. Shultz, From Informed Consent to Patient Choice: A New Protected Interest, 95 YALE L.J. 219 (1985).

76. N.Y. PUB. HEALTH LAW $\$ 2805-d$ (McKinney 1985 \& Supp. 1993). Although the statute does not expressly say so, the required disclosure includes the option of no treatment. 
Georgia statute requires disclosure of the nature of the treatment, any of several specified risks, the likelihood of success, practical alternatives, and prognosis if treatment is declined ${ }^{77}$-although even the most sophisticated clinician may lack this level of knowledge, especially as it applies to her individual patient. ${ }^{78}$ Increasingly, the disclosure is evidenced by a written form signed by the patient prior to treatment, which recites both the risks disclosed to her and her voluntary consent to treatment. ${ }^{79}$

Within these general principles, most informed consent litigation centers around three issues. First, disputes arise concerning the physician's duty to disclose all material risks, which most jurisdictions define in terms of the reasonable foreseeability or medical significance of the risk. Courts sometimes measure materiality according to the numeric probability of an adverse medical outcome, but vary in the numerical standards that they employ. ${ }^{80}$ Courts have not clarified whether the probabilities that the physician provides should refer to the average risk to large populations or must instead refer to the risk to the smallest group of which the patient is a member and for which the risk information exists; the latter is far more relevant to the patient, but is also more difficult for the physician to determine.

The Supreme Court of California addressed this question very recently in a decision that is already controversial ${ }^{81}$ and that is likely to affect the doctrine in other jurisdictions, given this court's influence in the informed consent area. ${ }^{82}$ In Arato v. Aiedon, ${ }^{83}$ the court considered a claim by a deceased pancreatic cancer victim's widow and children that his physicians' failure to disclose information concerning the statistical life expectancy of pancreatic cancer patients violated their duty to obtain his informed consent. ${ }^{84}$

\footnotetext{
77. GA. CODE ANN. § 31-9-6.1 (1991).

78. Telephone Interview with Dr. Ralph Horwitz, Professor of Medicine, Yale University School of Medicine (May 11, 1993).

79. See infra note 189 and accompanying text.

80. Compare Yeates v. Harms, 393 P.2d 982, 991 (Kan. 1964) (not requiring disclosure of very small chance of loss of eye) with Wilson v. Scott, 412 S.W.2d 299, 303 (Tex. 1967) (requiring disclosure of one percent chance of loss of hearing). In a recent case, the Maryland Court of Appeals held that a surgeon infected with the HIV might be negligent for having failed to inform patients of that condition before operating on them, despite the absence of any documented instance of HIV transfer from surgeon to patient in a sample of 4703 cases. The court emphasized that although the risk of transmission was "extremely low," death was almost certain if transmission did occur. Faya v. Almaraz, 620 A.2d 327, 333 (Md. 1993).

81. See Diane M. Gianelli, Ruling Sets Limit on Informed Consent, AM. MED. NEwS, Nov. 1, 1993, at 1 (citing criticisms of decision by some leading academic experts on informed consent).

82. Its seminal informed consent decisions include Cobbs v. Grant, 502 P.2d 1 (Cal. 1972), Truman v. Thomas, 611 P.2d 902 (Cal. 1980), and Moore v. Regents of University of California, 793 P.2d 479 (Cal. 1990), cert. denied, 111 S. Ct. 1388 (1991). A lower court decision in California, Salgo v. Leland Stanford Jr. Univ., 317 P.2d 170 (Cal. Ct. App. 1957), was also quite influential.

83. 23 Cal. Rptr. 2d 131 (1993).

84. The opinion fails to clarify precisely what the plaintiffs were claiming the physicians should have disclosed. Three possibilities are his individual life expectancy, the life expectancy of a larger group of which he was a member, or the more general information that the proposed treatment was unlikely to save his life. The court did not indicate that the first datum was available, cited testimony that the second would have been "inherently unreliable," $i d$. at 139 , and stated that the jury could have found that the physicians in effect did disclose the third, $i d$. at 140.
} 
The plaintiffs alleged that if the decedent had been properly informed of the high probability of early death, he would not have submitted to a painful therapy and would have averted the economic losses that resulted from his failure to put his business and financial affairs in order promptly. While upholding a jury verdict for the defendant and reaffirming the patient-based standard of disclosure, the court nevertheless held that no rule of law mandated the disclosure of specific information (including statistical life expectancy) "beyond that implicated by the risks of death or serious harm and the potential for complications" from a given treatment, ${ }^{85}$ that the duty to disclose any additional information should be defined by professional standards, and that expert testimony was admissible for this purpose. ${ }^{86}$ Finally, the court emphasized the importance of the jury's role in evaluating the factual context to determine the sufficiency of the disclosures. ${ }^{87}$ In Part IV of this Article, I argue that courts should foster this "sensitivity to context" not only by securing the jury's fact-finding role but also by crafting and refining the legal rules of informed consent so that the doctrine distinguishes among different kinds of physician-patient settings when it defines the nature and scope of the duty to disclose. ${ }^{89}$

Second, disputes arise concerning a physician's duty to disclose alternatives. Physicians ordinarily must inform patients about the risks of declining treatment ${ }^{90}$ as well as other reasonable alternatives. In some jurisdictions, moreover, physicians must disclose the risks of even those procedures that are more hazardous than the treatment they are in fact recommending. ${ }^{91}$

Third, disputes arise concerning causation (or injury). Causation consists of two prongs. Injury causation-the undisclosed risk must have caused the patient's harm-is a necessary element of all informed consent claims, whether pertaining to health care decisions, product warnings, tort law generally, or other contexts. ${ }^{92}$ Decision causation-had the patient been properly informed,

\section{Id. at 143.}

86. Id. at 143-44. The court, moreover, held that the duty to disclose did not extend to information material to a patient's financial or other nonmedical interests. Id. at 141-42.

87. Id. at $139-40$.

88. Id. at 139 .

89. See infra discussion Parts IV.C and IV.D.

90. See, e.g., Battenfeld v. Gregory, 589 A.2d 1059, 1061, 1066 (N.J. Super. Ct. App. Div. 1991) (holding physician liable who said plaintiff could leave hospital if she signed form acknowledging departure against medical advice, but did not inform her of specific risks if she departed); Truman v. Thomas, 611 P.2d 902, 906-07 (Cal. 1980) (holding physician liable who failed to disclose risks of patient's refusal, despite physician's repeated urgings, to have Pap smear).

91. See, e.g., Logan v. Greenwich Hosp. Ass'n, 465 A.2d 294, 301-02 (Conn. 1983). There is no duty, however, to disclose risks associated with diagnoses other than that which the physician is, in fact, making. See, e.g., Pratt v. University of Minn. Affiliated Hosps., 414 N.W.2d 399, 402 (Minn. 1987).

92. Cf. Aaron D. Twerski \& Neil B. Cohen, Informed Decision Making and the Law of Torts: The Myth of Justiciable Causation, 1988 U. ILL. L. REv. 607, 617 ("As initially developed, the doctrine of informed consent followed the traditional tort analysis of allowing recovery for damages proximately caused by the violation of a duty. ... [T]he procedure must have caused the patient's harm (injury causation)."). 
she would have made a different treatment decision-is an additional requirement in informed consent law. ${ }^{93}$ The plaintiff patient's testimony on decision causation is ordinarily admissible, even though it is likely to be biased, offered with the clarity of hindsight, and influenced by the adverse outcome that in fact occurred. ${ }^{94}$ Perhaps for this reason, all states except Oklahoma and Oregon apply an objective test of decision causation (i.e., what treatment decision would a prudent person in the plaintiff's position have made "if suitably informed of all perils bearing significance?"). ${ }^{95}$

In most jurisdictions, the duty of disclosure is subject to certain exceptions. These include situations in which (1) complete and candid disclosure might adversely affect the patient's physical or psychological well-being ("therapeutic"); (2) the patient is incapable of giving consent by reason of mental disability or infancy ("incompetence"); (3) an emergency makes obtaining consent impractical ("emergency"); (4) the risk is either known to the patient or is so obvious as to justify a presumption on the physician's part that the patient knows of it ("actual knowledge" and "common knowledge"); (5) the procedure is simple and the danger remote and commonly appreciated to be remote ("known remote risk"); and (6) the physician does not know of an otherwise material risk and should not have been aware of it in the exercise of ordinary care ("physician's reasonable ignorance"). ${ }^{96}$

This, then, is the essence of the informed consent doctrine. Many physicians will surely find this summary of principles highly unrealistic as an account of what physicians-even those who deeply sympathize with their patients' desires to know about and choose the risks to which they will be exposed and who are scrupulously devoted to protecting and vindicating those

93. It is analogous to the requirement in a negligent diagnosis case that the plaintiff show that, had a correct diagnosis been received, she would have made a different choice with respect to treatment.

94. See, e.g., Fore v. Brown, 544 So. 2d 955, 956 (Ala. 1989); see also David E. Seidelson, Lack of Informed Consent in Medical Malpractice and Product Liability Cases: The Burden of Presenting Evidence, 14 HOFSTRA L. REV. 621 (1986) (discussing role of plaintiff testimony and evidence in proving cause-infact); Twerski \& Cohen, supra note 92, at 654-64 (arguing that doctrine's focus on cause-in-fact compromises patient autonomy goal); $c f$. Alan Meisel, The Expansion of Liability for Medical Accidents: From Negligence to Strict Liability by Way of Informed Consent, 56 NEB. L. REV. 51, 123-32 (1977) (explaining that "defective" informed consent in medical context approaches strict liability, allowing recovery even though treatment itself was non-negligent).

95. Canterbury v. Spence, 464 F.2d 772, 791 (D.C. Cir. 1972). The Supreme Court of California explained the reason for an objective test in a leading case: "We doubt that justice will be served by placing the physician in jeopardy of the patient's bitterness and disillusionment. Thus an objective test is preferable: i.e., what would a prudent person in the patient's position have decided if adequately informed of all significant perils." Cobbs v. Grant, 502 P.2d 1, 11-12 (Cal. 1972) (in bank).

In Oregon and Oklahoma, the standard is more subjective, defined in terms of what the specific patient, rather than an objective "prudent" patient, would have decided had the information been properly disclosed. Arena v. Gingrich, 748 P.2d 547 (Or. 1988); Spencer v. Seikel, 742 P.2d 1126, 1129 (Okla. 1987). In North Carolina, a court seemed to endorse such a subjective standard but was reversed by the state legislature. McPherson v. Ellis, 287 S.E.2d 892, 896-97 (N.C. 1982) (considering relative merits of both subjective and objective standards and deciding objective standard resulted in greater inequities); N.C. GEN. STAT. § 90-21.13(a) (1990) (imposing objective standard for informed consent). See generally Seidelson, supra note 94.

96. E.g., Pauscher v. Iowa Methodist Medical Ctr., 408 N.W.2d 355, 360 (Iowa 1987). 
interests-actually do in clinical practice. Some of these more consumeroriented physicians will harbor even more subversive doubts about whether effective implementation of these general principles can ever be feasible under the conditions of practice and at a socially acceptable cost. These are important questions, and I take them up in Part III, most pointedly in my consideration of the argument from utility.

\section{Consent in Health Care Treatment Decisions: A Comparative ANALYSIS}

In Part II, I described the central principles of informed consent in tort law generally, in products liability law, and in informed consent proper. Here, I isolate the key commonalities and differences between informed consent proper and its warning analogues in these other settings. By focusing attention on which features of the health care context are truly distinctive, meriting special disclosure obligations, and which are not, this comparison can help to inform the normative policy debate over whether the scope of informed consent requirements in health care delivery should be expanded, retained, or reduced.

In the comparative analysis that follows, I do not conclude that the physician-patient relationship is functionally equivalent to that between product seller and buyer or between other risk creators and risk bearers governed by tort law. I do not claim, therefore, that disclosure obligations in these settings should be the same. We do and should view the physician-patient relationship as different from the relationship between commercial buyers and sellers or between other risk creators and victims, and the law of informed consent should reflect these differences. On the other hand, the comparison reveals more similarities than one might suspect and more than the literature suggests.

These similarities should give pause to the advocates of more robust informed consent proper. The question is not whether informed consent proper should be identical to informed consent in these other settings (in my view, it should not), but whether it should be as different as it now is, or more different still. The purpose of this Article is to raise this question and then to suggest some ways in which we might answer it. At this point, however, no reliable answer is possible because the crucial cost-effectiveness issues have not been seriously addressed. ${ }^{97}$ The necessary analysis must not only consider the informed consent doctrine as it now exists. Even more important, as discussed in Part IV, the analysis should consider the doctrine as it might be altered and implemented in at least three respects: if physicians' ability to communicate risk information were improved; if the doctrine were to view informed consent in a more contextual, differentiated fashion; and if physicians

97. See infra note 182 and accompanying text. 
and patients were given greater latitude to customize their own informed consent regimes through contract.

\section{A. The Doctrines Compared}

In two important respects, the doctrine of informed consent imposes more onerous obligations on health care providers than it does on product sellers and other risk creators who may be liable to the plaintiff unless they can establish that she knowingly and voluntarily consented to the risk. In several other, less important respects, the doctrine demands less of health care providers.

First, health care providers are under a fiduciary duty to their patients, ${ }^{98}$ a duty that product sellers or most other risk creators do not owe. Thus, a physician must always act in the patient's interests, whereas product sellers can, within broad limits, ignore or even subvert their customers' interests. Indeed, the physician must go so far as to prefer the patient's interests to her own, acting as the patient's selfless, scrupulous, dutiful agent. This duty underscores the purpose of informed consent proper, which is not simply to provide information to empower the patient to protect her own interests, but also, and perhaps more important, to further the physician's responsibility to place the patient's interests above her own. Only through dialogue with the patient can a physician come to understand the contours of the patient's interests and, thus, be in a position to help advance them.

One implication of this fiduciary status is that the physician must make more complete disclosures to the patient than the product seller must make to the customer. Specifically, the physician must affirmatively disclose and discuss not only all relevant information about the proposed treatment and her reasons for recommending it, but also all reasonable alternatives, including nontreatment. ${ }^{99}$ In contrast, a product seller is under no affirmative duty to offer all information that its customer might want even if the customer asks for it, much less to discuss alternatives (i.e., its competitor's products).

A second difference concerns the relative cost of obtaining informed consent in the two milieus. Both physicians and product sellers are subject to a negligence standard with respect to the information that they must provide. For a physician, however, the cost of conforming to this standard is likely to be significant even for a routine operation..$^{100}$ The physician incurs a cost for

98. See supra note 72 and accompanying text.

99. For a discussion of the types of information that must be disclosed, which vary among different jurisdictions, see supra note $72-95$ and accompanying text.

100. If a physician reduces informed consent to a pro forma ritual, she might well violate the legal duty. See, e.g., Hondroulis v. Schuhmacher, 553 So. 2d 398, 421 (La. 1989) (holding that waming on form that surgery involved risk of "loss of function of body organs" was not "understandable communication of any specific real risk"); Parikh v. Cunningham, 493 So. 2d 999, 1001-02 (Fla. 1986) (stating that conclusive presumption that signed form constitutes valid informed consent arises only after statutory requirements of informed consent are present). 
the time that she spends engaging in a meaningful dialogue with the patient about risks. Even if this time is quite brief (as studies of existing practice reveal it to be), ${ }^{101}$ the level of physicians' compensation today ensures that the cost in physician time will be significant. The fact that physicians ordinarily are compensated by procedure rather than by time does not alter this conclusion, for time (along with requisite skill) is probably the single most important component of provider fees. This factor also gives physicians an incentive to minimize the time that they spend on the procedure, including the time they spend obtaining a patient's consent. Regardless of the specific payment method for health care, the cost of additional time is likely to be passed on to payors (patients, insurers, government) in some form (either higher fees, premiums, or taxes; or fewer services or lower quality service). Informed consent discussions may also have other, more subtle effects on treatment, which are less readily measured but of equal or greater concern. ${ }^{102}$

In contrast, the primary cost a product seller incurs in warning consumers of potential danger is the cost of ascertaining the product's risks, which in most cases is already an explicit part of the product development process. The pharmaceutical, automobile, and medical device industries are prominent examples. ${ }^{103}$ Disseminating that information is likely to entail little additional cost. Once a product seller produces the requisite warning, it can simply and routinely disseminate it by affixing an identical label to each product. The marginal cost to the product seller of each warning after the first is negligible. In comparison to physicians, a product seller's only cost disadvantage in obtaining informed consent is that the product seller must gain the consumer's attention in order to communicate information. In contrast, the physician presumably has already engaged the patient in conversation, however brief and desultory.

There is, of course, another side to informed consent's doctrinal ledger, one that tends to favor health care providers relative to product sellers and other tort defendants. First, a product plaintiff can prove cause-in-fact (i.e., that

101. Howard Waitzkin, Doctor Patient Communication: Clinical Implications of Social Scientific Research, 252 JAMA 2441, 2442 (1984) (tape recordings of 336 doctor-patient encounters in variety of clinical settings indicate that, in an average 20 -minute encounter, physicians spent on average one minute giving information to patients; physicians overestimated amount of time giving information by about a factor of nine). Another study of informed consent in colonoscopy procedures found that, on average, patients reported having spent 20 minutes with their doctor discussing the decision to undergo the test; doctors reported an average of 13 minutes. Jennifer S. Mark \& Howard Spiro, Informed Consent for Colonoscopy: A Prospective Study, 150 ARCHIVEs INTERNAL MEd. 777, 777-78 (1990). This physicianpatient difference could result from different perceptions regarding what portions of the dialogue constitute part of the decisionmaking process.

102. One close student of clinical medicine observes, "application of this procedure to all decisions for all patients would convert the commonplace into the extraordinary and might serve to paralyze customary clinical practice." Interview with Dr. Ralph Horwitz, supra note 78.

103. See, e.g., THE LiabiLITY MAZE: THE IMPACT OF LiabiLITY LAW ON SAFETY AND INNOVATION 120-224, 291-360 (Peter W. Huber \& Robert E. Litan eds., 1991) (pharmaceuticals and automobiles). See generally STEVEN GARBER, PRODUCT LIABILITY AND THE ECONOMICS OF PHARMACEUTICALS AND MEDICAL DEVICES (1993). 
the warning defect actually caused the injury) more easily than a patient can, because the product victim can rely on the four presumptions discussed earlier. ${ }^{104}$ By contrast, the patient must adduce direct evidence to establish the necessary causal connections. Second, a finding that a product seller failed to obtain the requisite consent has a greater precedential effect than in the health care setting. Since product warnings are the same for all products bearing that label, while physician-patient dialogues are ideally more focused on the individual patient and her state of mind, a physician can more easily distinguish an unfavorable precedent and avoid liability than can a product seller.

Thus, some aspects of informed consent are more onerous for physicians than for other tort defendants while other aspects of informed consent are less onerous. Does this mean that the comparison is a wash and that physicians' duty to obtain informed consent is no more burdensome than that of other tort defendants? I think not. The aspects of informed consent that demand more from physicians (the scope of the duty and the clinical context) directly regulate their conduct and impose real costs, while the aspects that demand less from them (causal presumptions and precedential effect) instead concern the process of informed consent litigation, which appears to be relatively rare $^{105}$ and shapes physician practice only indirectly. On balance, then, informed consent doctrine imposes greater burdens on physicians than on other risk creators who are subject to more limited (or even nonexistent) duties to warn. ${ }^{106}$ The interesting question is why.

104. See supra text accompanying notes $69-70$.

105. In one empirical study of medical malpractice claims, only $1 \%$ of the claims against physicians and $2 \%$ of those against hospitals were classified as "failure to instruct patient." NATIONAL ASS'N OF INS. COMM'Rs, Medical Malpractice Closed Claims 1975-1978, in 2 MALPRACTICE Claims: FinAL COMPILATION 456, Tables 6.9 and 6.10 (M. Patricia Sowka ed., 1980). In other studies, the claims categories are too broad and highly aggregated to enable one to identify those cases that involve informed consent claims. See, e.g., U.S. GEN. ACCOUNTING OFFICE, MEDICAL MALPRACTICE: CHARACTERISTICS OF CLAIMS CLOSED IN 1984, at 76 (1987) ("[o] ther" category includes "failure to follow consent policies" as well as seven other subcategories); PATRICIA DANZON, MEDICAL MALPRACTICE: THEORY, EvIDENCE AND PUBLIC POLICY (1985) (discussing overall effect of four reforms, including those related to informed consent, but not distinguishing among them). Randall R. Bovbjerg, a health policy researcher at the Urban Institute, brought these examples to my attention. Telephone Interview with Randall $\mathrm{R}$. Bovbjerg, Senior Research Associate, Urban Institute (Oct. 4, 1993).

106. There are several doctrinal differences between the informed consent obligations of physicians and those of others, but these do not amount to much of a distinction in practice. First, as we have seen, a physician's duty to obtain informed consent is measured in some jurisdictions by the standard of the profession, while a product seller's duty is measured by a reasonableness standard. However, this distinction collapses if, as has been suggested, professional custom seldom, if ever, deviates from reasonableness. See Richard A. Epstein, The Path to The T.J. Hooper: The Theory and History of Custom in the Law of Tort, 21 J. LEGAL STUD. 1 (1992). Second, in the health care context, expert testimony may be required to establish the standard of informed consent. See Pauscher v. Iowa Methodist Med. Ctr., 408 N.W.2d 355 (Iowa 1987) (noting that expert testimony is ordinarily required). This may advantage physicians if they have greater access to experts than do product sellers. Third, if a physician can show that a more demanding disclosure would have posed a risk to the patient's medical condition or outcome, she need not make it. See, e.g., Pauscher, 408 N.W.2d at 360 . While a product seller cannot assert this "therapeutic" defense, she may achieve a similar result through a "reasonableness" defense. If the seller can show that a more extensive disclosure would simply have confused the consumer by creating "information overload," 


\section{B. Can the Greater Informed Consent Burden on Physicians Be Justified?}

This Section seeks to develop a more critical perspective on informed consent doctrine by exploring possible justifications for the more onerous disclosure obligations that the law imposes on physicians, justifications to which neither courts nor commentators appear to have given much thought. ${ }^{107}$ The strongest justificatory arguments proceed from concerns about individual autonomy, relational continuity, conflicts of interest, inequalities of power and information, and utility. My consideration and appraisal of these five arguments leads me to two conclusions. First, these arguments provide weaker support for the relatively demanding informed consent requirement in health care than is sometimes supposed. Second, powerful dynamics in the health care system that are pushing physician-patient relationships in a more cost-conscious, bureaucratic direction are at once undermining some of these arguments and reinforcing others.

\section{The Argument from Individual Autonomy}

The most fundamental normative argument in favor of requiring health care providers to obtain patients' informed consent to medical treatments proceeds from the principle of autonomy-the notion that each mature individual has a right to make the basic choices that affect her life prospects. ${ }^{108}$ The more private the choice-that is, the more it concerns the integrity of the individual's own projects and self-conception and the less it directly affects others-the more robust this right should be. Few if any choices are more private and intimate than those that concern the use made of one's own body, and thus society should not permit one's bodily integrity to be threatened by another unless one has knowingly and voluntarily consented to (i.e., willed) the intrusion. ${ }^{109}$

The autonomy principle is deeply entrenched in our culture and law; few exceptions to it-compulsory immunization ${ }^{110}$ and military conscription ${ }^{111}$ are the major examples-have been recognized. This principle, however,

the seller may be excused from providing the more complex disclosure. See cases cited in Schwartz, The Beginning and the Possible End, supra note 16, at 666 n.342.

107. For several exceptions, see Seidelson, supra note 94, at 647-51, and Twerski \& Cohen, supra note 92.

108. This view is advanced most elegantly in KATZ, supra note 1, at 104-29. For a recent review of the law's treatment of autonomy, see Bruce J. Winick, On Autonomy: Legal and Psychological Perspectives, 37 VILL. L. REV. 1705 (1992).

109. This argument dates to the origins of the informed consent in the common law doctrine of battery. See Schloendorff v. Society of N.Y. Hosps., 105 N.E. 92 (N.Y. 1914) (doctor performed additional medically necessary but unauthorized procedures during surgery); Rolater v. Strain, 137 P. 96, 97 (Okla. 1913) (barring physician from performing surgery without patient's consent).

110. See, e.g., Jacobson v. Massachusetts, 197 U.S. 11 (1905) (upholding compulsory immunization).

111. See, e.g., Gillette v. United States, 401 U.S. 437, 461 (1971) (upholding selective service system against religious challenge to conscription). 
applies no more strongly to medical choices than to other choices that alter the status quo and risk bodily injury, such as a decision to consume alcohol or to drive a fast car. Each choice equally implicates the autonomy principle in that each requires a tradeoff between an imagined benefit and a risk of personal harm. Treatment decisions can, but need not, entail risks of bodily harm and other adverse consequences more grave than those entailed by other choices. The same patient who receives medical treatment from a physician may also consume an over-the-counter drug. Both of these interventions implicate the patient's autonomy; the drug physically invades the body while the treatment may or may not. The patient surrenders some control to an external agent in both cases. Why, then, is the physician's informed consent duty far greater than that of the drug manufacturer?

The value of autonomy, moreover, is a function of the range of choice realistically available to the individual. In some areas of medical care, such as treatment for breast cancer, the patient may have a number of options (e.g., lumpectomy, single or double mastectomy, radiation, chemotherapy, and close surveillance). But in other medical situations, including some acute episodes, a patient has few (or no) practical alternatives from which to choose. For example, if an operation is needed to save her life, the patient may face a Hobson's choice. In other risky activities, by contrast, many choices (and thus many occasions for exercising meaningful autonomy) are usually available. Most consumers, for example, regard as salient a large number of product characteristics (e.g., performance, appearance, cost, durability, warranty terms), whereas patients who have already selected their providers (at least the vast majority who are insured) usually focus on but two dimensions of the treatment: the prospect of pain or discomfort, and the probabilities of various medical outcomes. ${ }^{112}$ To put the point another way, certain nonmedical activities may implicate that part of autonomy concerned with the expression of personality through the exercise of idiosyncratic choice more than medical care does.

Finally, the existing doctrine of informed consent proper (the law in books) is in one important sense inconsistent with a thoroughgoing commitment to individual autonomy. Under this doctrine, the only kind of injury that can constitute a compensable harm is an adverse medical outcome. A physician may with impunity flagrantly deny her patient the choice to which the patient's right of informed consent entitles her so long as she renders the treatment

112. See Mark \& Spiro, supra note 101 , at 780 ("Informed consent is ubiquitous in medical practice, but patient autonomy in medical decision making is not supported by most patients or physicians. ... [A]utonomous decision making by an informed and self-sufficient patient is probably rarer in clinical practice than in philosophical suggestion."). 
competently, and she leaves the patient no worse off medically than before. ${ }^{113}$

\section{The Argument from Relational Continuity}

One can argue that the physician-patient interaction is best viewed not as a single transaction but rather as a long-term, continuing relationship. In this view, the proper analogy for thinking about the distinctive features of informed consent proper is not conventional private law, which typically governs episodic exchanges between product sellers and buyers or interactions between risk creators and victims who are strangers. Instead, the argument runs, a better analogy is to long-term relational contracts, ${ }^{114}$ intrafamilial torts, ${ }^{115}$ and other regulatory domains such as the law of the workplace, which govern more complex relationships involving mutual dependency, emotional attachments and vulnerability, and collaboration over time.

Even if this relational continuity accurately characterizes many physicianpatient interactions in the past and many of those that continue today, it has not been present in many situations in which informed consent is likely to be most important. Surgical anesthesiology, for example, is performed by physicians with whom the patient ordinarily has no prior or subsequent relationship. Surgery often (and hopefully) involves only a one-time encounter. Many physicians who prescribe birth control pills have little contact with the patient thereafter.

For better or worse, the traditional image of the intimate, protracted relationship between physician and patient has grown increasingly anachronistic. Today, health care providers are abandoning the decentralized, family practice model in favor of delivery systems that assign enrolled patients to a series of professionals whom the patients do not know. Even if the idealized vision of physician-patient interactions continues to be that of a longstanding relationship based on personal intimacy and earned trust, it seems safe to predict that most health care in the future will be delivered in a highly bureaucratic-technocratic context that discourages such relationships. In this context, informed consent cannot credibly function as the dialogic expression of a relationship that no longer exists. Instead, health care interactions will come to resemble the commercial sales and other episodic transactions to which less demanding informed consent requirements apply in other areas of tort law.

113. Commentators have severely criticized this limited conception of the harm suffered by a patient who has been deprived of full, informed choice. See, e.g., KATZ, supra note 1, at 82-84; Schultz, supra note 75 , at 228-29, 298.

114. See, e.g., Charles J. Goetz \& Robert E. Scott, Principles of Relational Contracts, 67 VA. L. REV. 1089 (1981).

115. See generally PROSSER \& KEETON, supra note 13, at 901-39. 


\section{The Argument from Conflict of Interest}

A third argument for a demanding informed consent requirement in health care rests on the recognition that a physician's interests can conflict with those of her patient, and that more demanding informed consent requirements provide the appropriate legal shield against this possibility. ${ }^{116}$

When health care is provided on a fee-for-service basis, the physician's revenue increases with the volume and complexity of care that she provides. Current third-party payor arrangements further desensitize both patient and physician to economic tradeoffs; at the margin, this system creates a bias in favor of additional care even when cost-effectiveness and risk-benefit considerations would dictate less care. ${ }^{117}$ By contrast, in a health maintenance organization (HMO) or other pre-paid capitation system, the provider organization increases its profits (and thus, indirectly, the physician's) by limiting service (subject, of course, to market and malpractice constraints). In both the fee-for-service and HMO sectors, a provider's interests may favor more or less care than a fully informed patient (especially a cost-sensitive one) would want or choose.

I emphatically do not suggest that economic factors alone dictate providers' decisions. In fact, ethical norms, fiduciary duties, reputational concerns, and the threat of malpractice liability would strongly constrain provider behavior even if no independent economic incentives existed. At some margin, however, the economic interests of provider and patient do diverge, and this margin will grow wider as the health care system becomes more costconscious. We should not imagine, moreover, that economic conflicts of interest between physician and patient are the only kind at issue; their complex emotional relationship provides fertile soil for psychodynamic conflicts as well. ${ }^{118}$

116. See, e.g., Moore v. Regents of University of California, 793 P.2d 479 (Cal. 1990), cert. denied, 111 S. Ct. 1388 (1991).

117. See, e.g., Robert Pear, Doctors Assailed in Antitrust Move, N.Y. TIMES, Nov. 2, 1993, at A25 (discussing Federal Trade Commission use of antitrust laws against joint ventures formed by doctors who sent patients to equipment companies in which doctors had invested).

118. Professor Katz noted:

Physicians' quest for political power mirrors the quest for interpersonal domination of the physician-patient relationship. The public's reluctance to delegate exclusive authority to one group of healers during most of medicine's history may have been symptomatic of its misgivings over the unquestioned trust and obedience that doctors demanded from their patients. These misgivings could be voiced openly in situations when the public was not in direct contact with doctors, while in more intimate encounters patients could only express them passively and silently through noncompliance with their doctors' orders.

KATZ, supra note 1, at 46-47; see also id. at 85-86 ("[T]he idea of sharing the burdens of decision with patients will create new tensions; it will also bring to the surface old tensions that solitary decisionmaking has obscured."), and at 142-50 (analogizing to emotional tensions of the analyst-patient relationship). Some commentators have emphasized the powerful psychodynamics unleashed by product advertising and purchasing. See, e.g., VANCE PACKARD, THE STATUS SEEkERS 307-19 (1959). 
Without minimizing the importance of these provider-patient conflicts, the crucial point for present purposes is that they pale in comparison to the conflicts of interest that divide product seller and consumer and that divide risk creators and risk bearers in other areas of tort law. In accidents between strangers (the classic case is a vehicular collision), the interests of those who create risks and those who bear them are in far greater conflict. There, the extralegal concerns - competitive, reputational, and ethical-that make health care and product risk creators mindful of potential victims' interests are weaker or wholly absent. And yet, in these other areas, courts apply less stringent disclosure requirements to risk creators and limit their liability by recognizing defenses such as assumed risk and contributory fault. In product markets, a seller's interest in profit maximization is relatively unconstrained; it is limited only by products liability law's less robust, nonfiduciary duty to warn. ${ }^{119}$

\section{The Argument from Inequality of Information and Power}

A fourth argument for a more demanding informed consent requirement in health care emphasizes the imbalances in information and bargaining power that permit providers to exploit their patients. Surely such imbalances justify requiring providers to disclose treatment risks and rationales to patients before obtaining their consent. The more interesting question, however, is whether these imbalances justify making the informed consent obligation more demanding in health care than in other areas, especially products liability.

In both the health care and consumer product contexts, sellers are more likely than purchasers to know or be able to learn cheaply about the risks inherent in the treatment or product. But is the physician-patient disparity in access to relevant risk information greater than the disparity between product sellers and purchasers? Are product choices in general better informed than treatment choices?

These are difficult questions, but in each case the answer is not obviously "yes." Since most treatment and product risks are quite low, ${ }^{120}$ both patients

119. In both product and health care markets, of course, extralegal pressures-which are based on competitive, ethical and reputational concerns-also operate to encourage fuller disclosure. These pressures are probably more powerful than the legal ones with which this Article is concerned.

120. Even comparing medical treatment and product risks along a single dimension, such as magnitude, is difficult. Thanks to a recent study of medical malpractice, the most comprehensive ever conducted, the data on treatment risks are relatively good. This study reported that adverse events (defined as "unintended or unexpected harmful consequences of medical intervention ... that prolonged the hospitalization beyond the time required by the underlying illness and/or caused disability at the time of hospital discharge or death") were suffered by $3.7 \%$ of hospital patients in New York in 1984. Of these adverse events, one quarter (27.6\%) were due to provider negligence rather than to natural causes or nonnegligent care. This means that just under $1 \%$ of hospital patients suffered adverse events due to negligence. PAUl C. Weiler et AL., A MEASURE of MALPRACTICE 35, 43 (1993). About 14\% of the adverse events (and $25 \%$ of the negligent ones) resulted in death. Id. at 44 , Table 3.2. Because the study counted as deaths from adverse events those in which the treatment merely hastened an already imminent death, a more accurate measure of the risk of serious injury is the fraction of adverse events that caused 
and product consumers tend to estimate them poorly on their own. ${ }^{121}$ But the uncertainty surrounding many treatments means that even physicians are not omniscient about treatment risks; in some situations the disparity between their own ignorance and that of their patients may be no greater than that between the sellers and buyers of technologically complex products. Compared to most product risks, some common treatment risks-such as those associated with iatrogenic illnesses - are relatively large, and patients may know more about them than consumers know about most risks associated with the products they purchase. ${ }^{122}$

Patients often do confront information inequalities greater than those faced by product consumers and other potential risk bearers. Many health services are "credence" goods, whose evaluation depends on the opinion of experts (usually physicians) who act as gatekeepers to treatment; in contrast, most consumer products are either "search" goods, whose qualities consumers can ascertain by prepurchase inspection, or "experience" goods, whose qualities consumers can determine after they have consumed them. ${ }^{123}$ Product

severe to total permanent disability, which was $3 \%$ (or $0.03 \%$ for hospitalized patients overall). Id.; Telephone Interview with Professor Paul C. Weiler, Harvard Law School (Sept. 30, 1993).

When we turn to product risks, the data are more sparse and the situation is murkier. Letter from W. Kip Viscusi, Professor of Economics, Duke University, to author (Oct. 8, 1993). The annual risk of death from cigarette smoking ( 1 in 150) is much higher than that from medical treatment in hospitals. The annual risk of fatal accidents in the home from all causes is 1 in 11,000. W. KIP VISCUSI, SMOKING: MAKING THE RISKY DECISION 24 (1992). But the risk of death from products, which is only a subset of this broad category, is uncertain, and the risk of serious injury from products is even more uncertain. For most products, these risks are probably much lower than those from medical treatment. For some dangerous products, however, the risks may be higher than for medical treatment.

121. See VISCUSI, supra note 120, at 22-34; JUDGMENT UNDER UNCERTAINTY, supra note 24, at 46389 (on perceived risk of actual incidents). According to a leading researcher in this field, "[o]ur studies suggest people do a horrible job of making decisions with respect to risks on the order of 1 in a million, but once we get to a denominator in the range of 10,000 their responses start to make sense." Letter from W. Kip Viscusi to author, supra note 120.

People estimate risks differently depending on the context of the risk assessment and the specific character of the risk involved. James R. Bettman et al., Cognitive Considerations in Presenting Risk Information, in LEARNING ABOUT RISK: CONSUMER AND WORKER RESPONSES TO HAZARD INFORMATION 13, 14 (W. Kip Viscusi \& Wesley A. Magat eds., 1987) (people overestimate risks that receive media attention but underestimate risks of products they have used previously without injury); W. Kip Viscusi, Do Smokers Underestimate Risks?, 98 J. POL. ECON. 1253, 1253 (1990) (both smokers and nonsmokers greatly overestimate lung cancer risk from smoking and extent of overestimation is much greater than extent of underestimation); W. KIP VISCUSI, FATAL TRADEOFFS 70-73 (1992) (summarizing survey evidence on individual risk valuations of nonfatal health risks).

122. If knowledge of these risks is common enough among patients, a disclosure obligation may not be triggered in the first place. See note 96 and accompanying text ("common knowledge" exception). There are also analogous exceptions with respect to product wamings and assumed risk. See, e.g., Neff v. Coleco Indus., 760 F. Supp. 864,868 (D. Kan. 1991) (finding no duty to warn of risk of diving head-first into four-feet deep pool with which plaintiff was familiar), aff'd mem., 961 F.2d 220 (10th Cir. 1992); Joseph E. Seagram \& Sons v. McGuire, 814 S.W.2d 385, 388 (Tex. 1991) (finding no duty to warn of risk of alcoholism from excessive consumption of alcoholic beverages since "[f]rom ancient times, the danger ... has been widely known and recognized."); cf. Armentrout v. FMC Corp., 842 P.2d 175, 181 (Colo. 1992) ("If the danger is open and obvious, there is no duty to warn unless there is a substantial likelihood that the proposed warning would have prevented injury to the ordinary user.").

123. The distinction between search and experience qualities of consumer goods was developed by Phillip Nelson, Advertising as Information, 82 J. POL. ECON. 729, 730 (1974); Phillip Nelson, Information and Consumer Behavior, 78 J. POL. ECON. 311, 312 (1970). For a discussion of credence goods, see 
consumers, moreover, are more likely than health care consumers to be repeat purchasers. Consumer products also tend to be more standardized than health services, which must often be tailored to patients' particular characteristics. And, as noted earlier, physicians are already in some dialogue with their patients when informed consent obligations arise, while product sellers who wish to warn of product risks must first undertake the very difficult task of winning the consumer's attention amid the babel and clamor of competitors in the market. This difference may affect the cost of providing the information upon which consent can be based.

While such differences exist and are often important, one should not exaggerate either their universality or their magnitude. In fact, numerous exceptions to these generalizations exist. For example, consumers treat as credence goods some expensive, infrequently purchased products such as automobiles, homes, and pension funds. On the other side, patients treat some medical treatments as experience goods that they can evaluate independently according to how they feel the treatments have affected them. Repeat purchase of some medical services is common; two prominent examples are psychotherapy and chiropractic treatment. The standardized goods criterion also fails to distinguish patients from product consumers. For example, many clinical tests, vaccinations, and some other health services are uniform for all patients, while product consumers vary greatly in how they value the various attributes of even the most standard products. Different consumers also use standard products in quite different ways. ${ }^{124}$

These factors muddy, but do not wholly eliminate, the health care product distinction with respect to information inequality. Still, the considerations just discussed suggest that the size of the information gap is not invariably so much larger in health care than in product markets as to explain fully the greater demands of informed consent doctrine in health care. At the very least, the analysis suggests that even if the informational inequality between physician and patient justifies more demanding informed consent duties in certain health care contexts, it does not justify the current legal regime, which fails to differentiate disclosure duties adequately and tailor them to particular contexts and preferences. This point is discussed at greater length in Part IV.

The argument from inequality of bargaining power (which depends in part on information asymmetries) is in some respects even murkier than the argument from informational inequality. First, it is not clear how bargaining power should be measured, for it depends on a number of factors, including conditions of supply and demand, the distribution of information, the

Michael R. Darby \& Edi Karni, Free Competition and the Optimal Amount of Fraud, 16 J.L. \& EcoN. 67, 68-70 (1973).

124. Priest, Current Insurance Crisis, supra note 16, at 1548-49, 1557-58 (product warranties designed to reflect variations in optimal and actual product care and use patterns among different products and different consumers). 
availability of substitutes, and the nature of consumer psychology. In principle and often in fact, some health care consumers can select their providers and move from one to another if they are dissatisfied. Others cannot. Those who join "closed-panel" group practice plans like HMO's, for example, usually waive that freedom. Many patients who could shop for providers nevertheless fail to do so because of habit, ignorance, intimidation, lack of economic incentive, and the practice of referrals to designated specialists. Second, corporate and governmental budgetary pressures are forcing the health care delivery system to change in ways likely to enhance the future power of consumers in the aggregate, if not also individually. In particular, the system is moving relentlessly toward higher levels of organization, closer price and quality monitoring, and more intense competition among provider groups for access to patients. ${ }^{125}$

Even now, patients' bargaining power is not obviously or systematically weaker than that of consumers in products markets. Product consumers are not as well organized (except perhaps in purchasing cooperatives or monopsony situations such as government procurement) as health care consumers in the HMO and other sectors, in which employers and other large groups can and sometimes do act as consumer proxies. ${ }^{126}$ Even more anomalous from this perspective, individuals who make non-product, non-health-care choices-for example, people who unwittingly expose themselves to man-made environmental hazards-are even less organized than product consumers. These individuals do not usually contract with those who create the risks, as their product and health care counterparts do; they may not even know the risk creator's identity. Yet they are entitled to less information than even product purchasers, and far less than patients.

If patients possess weak bargaining power, their impotence is less the result of the structure of their choices about providers and treatments ${ }^{127}$ than of the set of deferential attitudes that many patients bring to their relationships with providers. These attitudes reflect, in part, anxieties about their health, their inferior social status vis-à-vis physicians, and their relative ignorance about medicine. ${ }^{128}$ What is less clear is whether the law of informed consent can or should do much to alter these attitudes-a question that is directly pertinent to the utility of the doctrine.

125. See, e.g., Paul Starr, The Logic of Health-Care Reform (1992); Dana Priest, A Health Care Primer: How 'Managed Competition' Would Work, WASH. POST, Mar. 9, 1993, at A1, A11.

126. See, e.g., Walton Francis, A Health Care Program Run by the Federal Government That Works, AM. ENTERPRISE, July/Aug. 1993, at 50 (describing Federal Employees Health Benefits Program).

127. Indeed, patients' choices have actually increased due to the growing surplus of physicians (especially in urban centers) and the improvements in health care technology.

128. See, e.g., NULAND, supra note 20, at 246-69; KATZ, supra note 1; Duffy, supra note 20, at 27-28. 


\section{The Argument from Utility}

A final argument for a more demanding informed consent duty in health care emphasizes the doctrine's usefulness to the patient who faces a treatment decision. Of all the arguments, this is in a sense the most straightforward. Although the doctrine has a number of aims, its most outcome-oriented goal is to inform and thus improve the treatment decision by assuring that the patient will receive crucial factual information about risks, benefits, alternatives, and reasoning. The argument from utility, then, seeks to justify the doctrine in terms of this goal.

Yet if the requirement elicits information that does not in fact affect, much less improve, the patient's decision, it is difficult to justify imposing the duty-unless it is costless or produces some good whose value does not depend on how efficacious the information is to the patient's treatment. Perhaps autonomy is such a goal, yet it is odd, even unintelligible, to speak of autonomy as desirable or useful unless the individual can actually exercise or enjoy it.

Actual utility, then, is arguably the most important criterion by which informed consent should be evaluated. ${ }^{129}$ The vast literature on informed consent, although much of it is empirical, ${ }^{130}$ fails to provide reliable answers to the crucial questions about how the doctrine actually works-the law in action. A 1983 survey, for example, noted that "there has been no really satisfactory empirical investigation of the central question: "What do doctors routinely tell patients?"'131 The same is even more true of another crucial question: What difference does it make? The discussion that follows summarizes the little that is known about these issues.

A priori, there are strong reasons to suspect that informed consent, at least the law in books, is often honored in the breach and almost impossible to enforce as a practical matter. Most of the existing empirical studies on informed consent support this intuition. These studies reveal three related

129. As Meisel and Roth noted:

The operation of such regulatory systems involves a substantial commitment of resources, which if they do not achieve their ends, might better be devoted to other forms of regulation or to no regulation at all. Furthermore, the imposition of legal requirements that are inefficacious and wasteful of scarce resources may foster contempt for law in general.

Alan Meisel \& Loren H. Roth, Toward an Informed Discussion of Informed Consent: A Review and Critique of the Empirical Studies, 25 ARIZ. L. REv. 265, 268 (1983).

130. Id. at 270.

131. Id. at 283 . One study indicates that while $90 \%$ of the physicians surveyed in 1961 preferred not to inform patients of a cancer diagnosis, $97 \%$ of physicians surveyed in 1976 routinely informed patients about such diagnoses. Dennis H. Novak et al., Changes in Physicians' Attitudes Towards Telling the Cancer Patient, 241 JAMA 897, 898 (1979). It is not clear from the study whether this revealed a change in physicians' preferences (perhaps arising out of the availability of improved treatment options) rather than in their behavior, and whether the change occurred because of informed consent doctrine or for some other reason. The recent Arato decision, see supra note 83 and accompanying text, attributes the change in part to intervening court decisions, but cites no evidence to support that supposition. Arato v. Avedon, $23 \mathrm{Cal}$ Rptr. 2d 131, 138 n.7 (1993); see also infra note 154. 
impediments to implementation of informed consent doctrine: (1) most physician-patient discussions appear to be rather perfunctory and reinforce physician control; (2) the treatment context discourages patients from exploiting the information that physicians do provide; and (3) the nature of the tort system makes it difficult for patients to establish an effective legal claim.

First, regardless of the formal doctrinal requirements, the usefulness of informed consent depends on a meaningful dialogue between physician and patient. Yet the minimally necessary ingredients of such a dialogue-questions by the patient, full and discursive responses by the physician that invite the patient to ask follow-up questions-are usually absent in most clinical situations. Studies indicate that patients rarely initiate a dialogue by asking questions, that physicians often discourage genuinely dialogic, open-ended discourse about treatment, and that patients seldom ask follow-up questions. ${ }^{132}$ Physicians discourage active, give-and-take dialogue. ${ }^{133}$ Although patients invariably sign the consent forms, this appears to have little effect on how patients actually make decisions. ${ }^{134}$ This is not at all surprising, especially when one considers that in many cases the crucial decision has been made well before the form is even presented for signing. ${ }^{135}$ Patients' recall of information, alternatives, and risks is low. ${ }^{136}$ While the

132. As Meisel and Roth summarize the empirical findings, "information is not very actively provided by doctors to patients, nor do patients actively solicit information. Although doctors do not volunteer much information, when patients ask questions doctors tend to answer them, although it is not clear how fully and forthrightly." Meisel \& Roth, supra note 129, at 334; see also KATZ, supra note 1, at 84, 125; ChARLES WV. LIDZ ET AL., INFORMEd CONSENT: A STUdy OF DECISIONMAKING IN PSYCHIATRY 94-99 (1984); Cathy J. Jones, Autonomy and Informed Consent in Medical Decisionmaking: Toward a New SelfFulfilling Prophecy, 47 WASH. \& LEE L. REV. 379, 397-427 (1990) (presenting participant-observation study in hospital and reviewing other studies).

133. Meisel and Roth summarize the studies: "Information is given to acquiescent patients to obtain their compliance with treatment, and to resistant patients to overcome their opposition. . . . [P]atients either go along with or refuse to go along with doctors' recommendations." Meisel \& Roth, supra note 129, at 334. There is some evidence that the nature and scope of disclosures vary with the patient's socioeconomic status, that patients say that they want more information than they are getting, and that patients and physicians have different perceptions about the quantity and quality of information that is actually being discussed. PRESIDENT's COMM'N FOR THE STUDY OF ETHICAL PROBLEMS IN MEDICINE \& BIOMEDICAL \& Behavioral Research, MaKing Health CaRe Decisions: A Report on the ETHiCal and Legal IMPLiCATIONS OF INFORMEd CONSENT IN THE PATIENT-PRACTITIONER RELATIONSHIP, Volume ONE: REPORT 70-102 (1982).

134. See, e.g., LIDZ ET AL., supra note 132, at 318; Jones, supra note 132, at 400-04.

135. The most common example is the discussion between the patient and the anesthesiologist, which ordinarily takes place on the eve of surgery, after the patient has decided to enter the hospital and undergo the operation.

136. Meisel \& Roth, supra note 129 , at 295 . Although a number of studies show that patient recall, even shortly after the disclosures, is quite low with respect to risks and alternatives, recall and understanding are not the same. These studies, therefore, do not necessarily prove that the patient lacked understanding at the time of disclosure. Meisel and Roth discuss this point at length. Id. at 288-90, 292-95.

Interestingly, data from a very recent study of birth mothers indicate a remarkable degree of information recall by the mothers five years after delivery. Penny B. Githens et al., Accuracy of Maternal Recall of Risk Factors and Events During Pregnancy, Labor/Delivery, and Child's Early Infancy, BIRTH (forthcoming) (manuscript at 7 , on file with author). This finding might reflect the fact that the birth of one's child is perhaps the only hospitalization for a condition that is both desired and ordinarily leads to an altogether happy experience there-a circumstance that might make the events surrounding it vividly memorable. See infra note 214 and accompanying text. It might also reflect the emphasis, unusual in health 
studies shed very little light on the pivotal questions of how well patients understand and use the information that is disclosed, anecdotal and social science evidence alike demonstrate that informed consent law in action is often ritualistic, formalistic, and hollow. ${ }^{137}$ The disclosures do not appear to reduce significantly patients' dependency on, and deference to, their physicians. ${ }^{138}$ One revealing sign of the extent to which physicians orchestrate a more or less perfunctory process is a now-common locution among physicians. They do not say that they have obtained the patient's consent; rather, they say that they have "consented the patient."139

Second, the clinical treatment setting tends to discourage meaningful exchange of information. This fact can be explained in straightforward terms without assuming either that patients are irrational or that their physicians are autocratic. $^{140}$ The truth is that even reflective, highly rational patients-individuals who ordinarily and self-consciously seek information and weigh alternatives in making careful choices about their lives, and who are confident of their ability to do so-may not want much information about risks or alternatives in this particular context. This attitude should not be surprising given the costs to patients of acquiring the requisite information, in terms of fees for the physician's time, the patients' own time, and the anxiety and conflict that a more elaborate discussion might arouse. Instead, they may prefer to devote their limited resources to selecting a physician on whose judgment they are content to rely in making subsequent treatment decisions. ${ }^{141}$ These patients may reason that as one-shot decisionmakers (and often ill-informed, anxious ones at that), they will be prone to cognitive errors from which a more detached professional, who has honed her judgment over the course of numerous such decisions, will be relatively immune. As for the physician, her ritualistic compliance may be the result not so much of her arrogance as of her

care, on informing expectant mothers about the nature of the prenatal and perinatal processes that they are undergoing.

137. See, e.g., E.K. Stern et al., What Pediatricians Really Know About Immunizations and Informed Consent, 137 AM. J. DISEASES CHILDREN 530 (1983) (38\% of doctors thought consent should be obtained routinely but only $7 \%$ obtained written consent and $32 \%$ obtained verbal consent; only $39 \%$ warned about serious side-effects); Mark \& Spiro, supra note 101, at 778 (40 out of 102 colonoscopy patients believed their doctor was primarily responsible for decision to undergo procedure).

138. Jones, supra note 132 , at $397-425$.

139. Professor Henry Greely, Remarks at Vanderbilt University Seminar on Medical Malpractice (Apr. 15-17, 1993); Interview with Dr. Jonathan Katz, Associate Clinical Professor of Anesthesiology, Yale University School of Medicine, in New Haven, Conn. (Mar. 5, 1993).

140. For one account of the development of physician autocracy, see KATZ, supra note 1, at 1-47.

141. Consumers behave in a similar fashion when information is readily available but, for one reason or another, costly to assimilate. See, e.g., Edward L. Rubin, Legislative Methodology: Some Lessons from the Truth-in-Lending Act, 80 GEO. L.J. 233, 236 (1991) (despite mandated disclosure of annual percentage rate, consumer installment loan borrowers were unable to process information correctly). On the other hand, studies show that even experts make cognitive errors of their own. JUDGMENT UNDER UNCERTAINTY, supra note 24 , at 154 . 
fear of liability, even if that fear (the law in the mind) is unjustified. ${ }^{142}$ The physician's perfunctory behavior may also reflect a lack of training in how to communicate effectively with patients. ${ }^{143}$

I have been speaking here of reflective, highly rational patients. However, many patients, perhaps most, are neither reflective nor highly rational in this sense, especially in the clinical milieus in which informed consent is sought. Instead, they are often anxious, intimidated, and abjectly-even neurotically-inclined to acquiesce in their physician's professional judgment. ${ }^{144}$ If these considerations induce deference and passivity in many of the most rational, self-confident patients, they will surely influence the less reflective ones even more strongly.

A third obstacle to implementation of informed consent law in the books is the nature of the tort system. This system suggests that the doctrine cannot, except in the most egregious cases, be enforced effectively against physicians who are ignorant of it, evade it, or comply with it only formalistically. Patients are unlikely to recall long after the fact what a physician said to them; ${ }^{145}$ still less are they able to recall just how the information was communicated, which is even more pertinent to the doctrine's purposes. Other than the parties' own recollections, the only extrinsic evidence of the physician-patient conversation will probably be any notes that the physician entered in the patient's chart, and the consent form that the patient signed reciting that she heard and understood what was disclosed to her and that her decision was voluntary and informed. Thus, in the unlikely event of litigation, the case will consist of the patient's memory and word-biased (or so it may seem to the jury) by her adverse medical outcome-against the physician's.

Even if a patient can succeed in showing that her physician did not obtain the requisite informed consent, she will have difficulty proving that the lack of informed consent was the cause in fact of her unfavorable outcome. As noted earlier, courts have been understandably reluctant to presume that the patient, if properly informed, would have made a different treatment decision

142. For a discussion of analogous behavior, see PETER H. SCHUCK, SUING GOVERNMENT: CITIZEN REMEDIES FOR OFFICIAL WRONGS 73-75 (1983) ("self-conscious formalism" by officials fearing liability).

143. Medical school curricula are reportedly placing greater emphasis on teaching "bedside manner" now than in the past. James F. Blumstein, Remarks at Vanderbilt University Seminar on Medical Malpractice (Apr. 15-17, 1993). On the other hand, Dr. Jay Katz, a leading advocate for more comprehensive and meaningful physician-patient discussions, believes that his own strenuous efforts to educate medical students and doctors on the subject "have largely failed." Interview with Dr. Jay Katz, Elizabeth K. Dollard Professor Emeritus of Law, Medicine and Psychiatry, Yale Law School, in New Haven, Conn. (Mar. 22, 1993). These discursive difficulties do not appear to be confined to physicianpatient relationships in the United States; they seem to be universal. See INTERNATIONAL MEDICAL BENEFT/RISK FOUNDATION, IMPROVING PATIENT INFORMATION AND EDUCATION ON MEDICINES (1993).

144. KATZ, supra note 1 , at 125.

145. Indeed, recall appears to be poor even shortly after the event. See supra note 136; see also David A. Herz et al., Informed Consent: Is It a Myth?, 30 NEUROSURGERY 453,454 (patients remembered $43.5 \%$ of information immediately after disclosure, $38.4 \%$ four to six weeks later); Louise M. Wallace, Informed Consent to Elective Surgery: The 'Therapeutic' Value?, 22 Soc. SCI. MED. 29, 30-31 (1986) (review of studies; patients forget between $28-71 \%$ of information within minutes of doctor's verbal explanation). 
than she actually did, much less that this hypothetical decision would have produced a better medical outcome. ${ }^{146}$ Even more important, the generally low level of treatment risks ${ }^{147}$ means that the vast majority of those patients whose autonomy has actually been violated by their physicians' failure to obtain informed consent still cannot show the only kind of injury-an adverse medical outcome-that will support an award of damages under existing informed consent doctrine. ${ }^{148}$ It follows that the patient will have difficulty inducing a contingent-fee lawyer to take the case, however clear the violation of informed consent may be. ${ }^{149}$

Thus, both behavioral data and the structure of tort law provide reasons to doubt the degree to which informed consent in action actually benefits patients. ${ }^{150}$ Studies establish that many, though not all, patients say that they would prefer more discussion with their physicians about treatment options. ${ }^{151}$ If patients hold these preferences not only when questioned in the abstract but in the context of actual treatment and despite the additional costs

146. See supra note 95 and accompanying text.

147. See supra note 120 .

148. The outcome is less clear whether the requisite injury for an informed consent recovery exists in a situation where surgery was both consented to and successful, but was arguably unnecessary. Such claims, although unusual, are sometimes asserted. See Caesarean-Birth Verdict, WALL ST. J., June 17, 1993, at B8 ( $\$ 1.5$ million jury verdict in Massachusetts for illness triggered by allegedly unnecessary caesarean delivery).

149. Although no data on informed consent litigation per se exist, see supra note 105 , this conclusion finds support in empirical studies indicating that medical malpractice claims, of which informed consent claims are one subset, are unusually difficult for even meritorious plaintiffs to litigate and win, especially given state "tort reform" legislation. See, e.g., Neil Vidmar, The Unfair Criticism of Medical Malpractice Juries, 76 JuDICATURE 118, 119-20 (1992) (recent North Carolina study finds low plaintiff success rate and low median awards). Because informed consent claims often involve loss of the opportunity to choose (which is often not compensable) rather than an adverse medical outcome or physical harm, see supra note 113 and accompanying text, they are even less attractive to plaintiffs' lawyers than are traditional malpractice claims. Informed consent claims are often simply tacked on to these traditional malpractice claims, with the advantage that they do not depend on a showing that the physician provided negligent treatment. See, e.g., Aaron D. Twerski \& Nejl B. Cohen, Symposium, Comparing Medical Providers: A First Look at the New Era of Medical Statistics, 58 BROOK. L. REV. 5, 33 (1992).

150. The methodology of defining and measuring benefits from informed consent is, of course, controversial. A recent, unpublished review of empirical studies concludes (without citation) that the benefits of disclosure are "uncertain with respect to the medical injury rate." DON DEWEES ET AL., EXPLORING THE DOMAIN OF ACCIDENT LAW: TAKING THE FACTS SERIOUSLY 3-48 (forthcoming 1994). On the other hand, some studies indicate that disclosure is associated with increased personal satisfaction. See, e.g., Judith A. Hall et al., Meta-Analysis of Correlates of Provider Behavior in Medical Encounters, 26 MED. CARE 657 (1988) (review of empirical studies shows postvisit patient satisfaction associated with amount of information given by physician, but apparently without controlling for patient's medical outcome). One possible way to measure patient benefits is to seek to determine what patients would be willing to pay (or otherwise sacrifice) in order to receive various levels of information. This process might be accomplished through surveys or consumer simulation experiments.

i51. See, e.g., Howard Waitzkin, Doctor-Patient Communication: Clinical Implications of Sacial Scientific Research, 252 JAMA 2441, 2442 (1984) (physicians severely underestimate amount of information their patients desire); Kenneth D. Hopper et al., Patients' Attitudes Toward Informed Consent for Intravenous Contrast Media, 27 INVESTIGATIVE RADIOLOGY 362, 365 (1992) (patients particularly interested in risks of procedure); Wallace, supra note 145, at 30 (lack of information most common patient complaint); David B. Spring et al., Written Informed Consent for I.V. Contrast-Enhanced Radiography: Patients' Attitudes and Common Limitations, 151 AM. J. RoENTGENOLOGY 1243, 1243 (1988) (90\% of patients surveyed wanted risk information about procedure; $10 \%$ did not). 
of more information, then patients should reap at least affective benefits if the informed consent doctrine in books is more fully implemented. ${ }^{152}$

There is another reason, however, to doubt whether patients actually benefit from the physician-patient dialogue in the way that the doctrine envisions, and whether even reforming the health care system structurally would significantly alter this fact. The problems with physician-patient dialogues that I have described are not peculiar to the United States. They also appear in Canada, Europe, and Japan-countries whose organization of health care, political-regulatory structures, and professional culture and practices differ from ours in many fundamental respects. ${ }^{153}$ The fact that similar discursive patterns are universal-or at least are found in highly diverse contemporary health care systems-strongly implies that these patterns are so deeply rooted in the psychology and structure of a physician-patient relationship as to be largely immune to change through legal doctrine or other exogenous factors.

My skepticism about both the benefits of informed consent law in action and the prospects for the vigorous enforcement and efficacy of the law in books is not meant to suggest either that the informed consent process has been wholly meaningless or that it cannot be improved. There is some evidence that physicians now disclose more to patients than they did in the past. ${ }^{154}$ Moreover, reformers have made a number of useful proposals as to how informed consent might be made more meaningful and beneficial, and some interesting experiments have been conducted. ${ }^{155}$ In particular, the use of video presentations augmented by discussion seems very promising, ${ }^{156}$ and

152. See, e.g., Hall et al., supra note 150 , at 661 .

153. See INTERNATIONAL MEDICAL BENEFIT/RISK FOUNDATION, supra note 143.

154. See, e.g., Paul P. Lee et al., Is Informed Consent Needed for Fluorescein Angiography?, 111 ARCHIVES OPHTHAMOLOGY 327, 327 (1993); see also PAUL S. APPELBAUM ET AL., INFORMED CONSENT: LEGAL THEORY AND CLINICAL, PRACTICE 265-66 (1987) (noting recent efforts for medical students to improve implementation of informed consent); David A. Kessler, Communicating with Patients About Their Medications, 325 NEW ENG. J. MED. 1650, 1651-52 (1991) (encouraging physicians to communicate more meaningfully with patients about prescribed drugs, and noting trend among pharmacists to engage in such discussions); Novak et al., supra note 131, at 897-98.

155. See, e.g., P.J.D. Dawes et al., Informed Consent: The Assessment of Two Structured Interview Approaches Compared to the Current Approach, 106 J. LARYNGOLOGY \& OTOLOGY 420, 420 (1992) (structured interview using written information sheet improves patient recall of procedural risks without increasing preoperative anxiety); David L. Simel \& John R. Feussner, A Randomized Controlled Trial Comparing Quantitative Informed Consent Formats, 44 J. CLINICAL EPIDEMIOLOGY 771, 775 (1991) (patients can use quantitative information to make decisions); Melinda M. Hutson \& J. David Blaha, Patients' Recall of Preoperative Instruction for Informed Consent for an Operation, 73 J. BONE \& JOINT SURGERY 160, 162 (1991) (tutoring of patients may increase recall at moment of informed consent procedure of risks and benefits); Jon F. Merz et al., Verbal Expressions of Probability in Informed Consent Litigation, 11 MED. DECISION MAKING 273, 273 (1991) (recommending that physicians give patients standardized probabilistic definitions in verbal quantitative terms).

156. See, e.g., Michael M. Weinstein, Dr. Video: How Best To Decide What Patients Need, N.Y. TIMES, Dec. 13, 1992, at E16 (use of videotape during informed consent discussions reduced number of patients electing surgery in Denver HMO). In a March 19, 1993, interview conducted on a ski lift (and thus presumably in a spirit of candor, exhilaration, and full disclosure), an orthopedist told the author that most of his practice consisted of three distinct operations and that he had purchased, at a cost of $\$ 100$ each, videotapes that described each of these operations, which he plays for his patients. Cf. Deborah N. Ader et al., Information Seeking and Interactive Videodisc Preparation for Third Molar Extraction, 50 J. ORAL 
a third-party strategy utilizing paraprofessionals who are specially trained to communicate with patients in ways that many physicians apparently find difficult might also be fruitful. ${ }^{157}$

The problem, however, may well go beyond poor techniques and flawed implementation of the doctrine. As I have suggested, tort law is severely constrained in its ability to generate the hoped-for benefits from informed consent on the books. Tort law is particularly impotent when it seeks to alter behavior in the kind of settings in which informed consent proper is supposed to occur. ${ }^{158}$ Physician-patient discussions are conducted in private; little extrinsic evidence exists to contradict the physician's account. These discussions are already shaped by other deeply entrenched social forces, including physicians' superior status and long-established professional traditions, and patients' anxiety and medical ignorance. The discussions are documented by forms that courts are reluctant to look behind and thus usually deem authoritative. ${ }^{159}$ On the cost side, moreover, most of the changes that are practicable would require highly compensated professionals to spend more nontreatment time with patients, an issue to which I now turn.

\section{Would a More Demanding Informed Consent Doctrine Be Worth the Cost?}

In the previous Sections, I first showed that the informed consent doctrine in books is more onerous for health care providers than are the analogous doctrines for product sellers and other risk creators. I then considered the most plausible arguments supporting this difference and concluded that when these purported justifications are closely evaluated, they are not compelling-although the argument based on inequality of information and

MAXILLOFACIAL SURGERY 27 (1992) (interactive videodisc presentations convey information less successfully than ordinary videotapes, but achieve higher rates of satisfaction among patients). More generally, better ways of communicating risk information through visual representations other than videotape can be developed. See infra text accompanying note 198.

157. There are many examples of this third-party approach, including abortion counseling and pre-test counseling for HIV infection and other sexually transmitted diseases. For a striking example, see Frederick Wiseman's prize-winning film, NEAR DEATH, which records painstaking consultations between a psychiatrist (not the treating physician) and the family of a terminal patient. NEAR DEATH (Exit Films 1989). The Surgeon General's tobacco warnings, see infra notes 206-07, also exemplify a third-party strategy. See also Steven R. Smith, Mental Health Malpractice in the 1990s, 28 Hous. L. REv, 209, 258 n.302 (1991) (patient advocate could have role in initiating and reevaluating informed consent); Jones, supra note 132, at 426 (suggesting patient advocates).

158. Cf. Peter H. Schuck, Some Reflections on the Baby M Case, 76 GEO. L.J. 1793, 1808-10 (1988) (contract law, augmented by regulation, could enforce informed consent values in connection with surrogate parenting). See generally STEPHEN D. Sugarman, DOING AWAY WITH PERSONAL INJURY LAW (1989) (deterrent potential undermined by ignorance of law, incompetence, discounting of liability threat, and low penalties); Howard A. Latin, Problem Solving-Behavior and Theories of Tort Liability, 73 CAL. L. Rev. 677 (1985) (inattentiveness to task and difficulty of assessing risk limit effectiveness of tort law); Neil L. Komesar, Injuries and Institutions: Tort Reform, Tort Theory, and Beyond, 65 N.Y.U. L. REV. 23, 28 (1990) (deterrence depends on how well actors receive incentive signals).

159. See FURROW ET AL., supra note 73, at 377 ("The courts have had little to say about consent forms."). In many states, legislation reinforces this deference to the consent forms. Id. 
power has some force. In large part, I rejected these justifications because of both the informed consent gap (i.e., the marked difference between the law in books and the law in action) and the structural impediments to reducing that gap significantly through tort law. These impediments suggest that toughening the law in books by imposing even more demanding dialogic responsibilities on physicians would not succeed in closing, and might even widen, the informed consent gap. In this Section, I argue that the costs of attempting to close the informed consent gap in this manner would be high.

In one view of informed consent, the doctrine's practical consequences are less important than the values that it instantiates and promotes. From this Kantian perspective, the rigorous requirement is morally compelled-regardless of how well or poorly it actually achieves its goals, because the value of patient autonomy is paramount. This deontological view has driven the traditional doctrine of informed consent in American courts to a considerable degree. I do not mean that the courts are wholly indifferent to the costeffectiveness of informed consent in practice. Presumably, it is because they are concerned with costs that courts typically limit the disclosure mandate to risks that are "material" and not commonly understood, apply a less costly "objective" test of patients' information needs, recognize a number of exceptions to the disclosure requirement, and demand that plaintiffs demonstrate injury causation as well as decision causation. ${ }^{160}$ Nevertheless, the cases evince little systematic judicial interest in the doctrine's actual consequences, especially its costs. Instead, courts tend to invoke the values of autonomy and improved decisionmaking and then analyze the implications of those values, while maintaining a silence on the issue of costs. This mode of analysis assumes that the costs of advancing these values are either de minimis or not worth analyzing. ${ }^{161}$

Today, however, the policy environment in the United States bears little resemblance to that which prevailed more than three decades ago, when the informed consent doctrine was first formulated. ${ }^{162}$ In this new environment, the health care costs associated with legal requirements are simply too politically salient to be assumed away, especially if the benefits are in doubt. Concerns about these costs have fundamentally transformed public rhetoric and political agendas. President Clinton's proposals on national health insurance, whatever their eventual fate, have already triggered an intense congressional debate. A major focus of this debate, of course, is the problem of medical costs, which have been increasing for a long time at rates far in excess of

160. See supra notes 72-95 and accompanying text.

161. See, e.g., Faya v. Almaraz, 620 A.2d 327, 333 (Md. 1993) (duty of AIDS-infected surgeon to disclose); Kerins v. Hartley, 21 Cal. Rptr. 2d 621 (Ct. App. 1993) (same).

162. The generative decisions were Salgo v. Leland Stanford Jr. Univ., 317 P.2d 170 (Cal. Dist. Ct. App. 1957) and Natanson v. Kline, 350 P.2d 1093 (Kan. 1960). An early case, Hunter v. Burroughs, 96 S.E. 360,366 (Va. 1918), had prefigured such a doctrine in the most general terms. 
inflation in the nonhealth sector of the economy. In 1992, these costs amounted to approximately $\$ 900$ billion, consuming $13.9 \%$ of the gross domestic product. ${ }^{163}$ U.S. per capita GDP health care expenditures in 1990 exceeded those of Canada by $15 \%$, Germany by $20 \%$, France by $26 \%$, Japan by $22 \%$, and the United Kingdom by $40 \%{ }^{164}$ Already the highest in the world by any measure, these costs are still on a rising trajectory. ${ }^{165}$

In devising a politically viable, fiscally sound national health plan, policymakers confront many poignantly conflicting claims for additional resources. These include, for example, the claims of approximately thirty-five million uninsured individuals, the need for pregnancy and maternal care, neonatal care, childhood disease treatment, long-term care, mental health services, organ transplantation, heroic life-sustaining measures for the terminally ill, substance abuse treatment, preventive care, lead paint and (more controversially) asbestos removal, ${ }^{166}$ prescription drugs, and countless other genuine needs. Policymakers must somehow compromise these claims; they may have to reject some of these claims altogether.

Choices of this kind allocate scarce resources in ways that inevitably occasion great suffering or death, putting the moral foundations of social collaboration at some risk. ${ }^{167}$ If such "tragic" choices (as Guido Calabresi and Philip Bobbitt have characterized them) are now inescapable in health care, informed consent, like other policies concerned with health care delivery, should be weighed and balanced against other policies competing for those resources. As the United States moves from a market-organized and consumerdriven health care system to one in which patients must cede more of their autonomy and choice to cost-conscious public payors and regulators, the need to balance the costs and benefits of informed consent, or at least to maximize the social return on whatever costs the system incurs, will be even more compelling. This need exists, moreover, even though the informed consent process probably accounts for only a tiny fraction of the health care system's total costs. ${ }^{168}$

163. See Sally T. Burner et al., National Health Expenditure Projections Through 2030, HEALTH CARE FIN. REV., Fall 1992, at 1, 14 (finding that national health expenditures constitute 13.9\% of U.S. GDP).

164. George J. Schreiber et al., U.S. Health Expenditure Performance: An International Comparison and Data Update, HeALTH CARE FIN. REV., Summer 1992, at 1, 13.

165. According to one analysis, this cost increase reflects the relatively slow growth in the productivity of health care services, but high productivity growth in other economic sectors means that less labor time by health care consumers is needed to pay for these more costly services. See William J. Baumol, Do Health Care Costs Matter?, New RePUBLIC, Nov. 22, 1993, at 16.

166. See, e.g., B.T. Mossman et al., Asbestos: Scientific Developments and Implications for Public Policy, 247 SCIENCE 294 (1990) (describing wide variation in riskiness of different types of asbestos fibers and failure to account for differentiation in public policy discussions).

167. See Guido Calabresi \& Philip BobbitT, TRAGic Choices 17-18 (1978).

168. The same can be said (more or less) of most of the other policies under discussion, and even a tiny fraction of the whole could amount to a great deal of money. An example is medical malpractice, which is a prominent target of reform efforts but which accounts for only a small share (an estimated 1\%) of total health care costs. Frank Sloan, Remarks at Vanderbilt University Seminar on Medical Malpractice (Apr. 15-17, 1993). As it happens, a leading analyst of medical malpractice costs argues that informed 
Conceivably, a system that has grown sufficiently cost-conscious to make its tragic choices more transparent could opt for an informed consent law that is more, rather than less, demanding than existing doctrine. For example, a more cost-conscious system might accept the argument, noted below, that informed consent could actually reduce health care costs by producing better treatment decisions and more satisfied patients, who would be less likely to assert malpractice claims. ${ }^{169}$ Alternatively, it might take the view that the social benefits arising from greater patient autonomy outweigh the doctrine's costs, or that an even more robust informed consent is needed to counterbalance the growing bureaucratization and routinization of health care delivery.

Such a policy choice, however, seems most unlikely. Under a new, more cost-conscious system, patients who previously were free to choose any treatment that they wished while still being assured of third-party reimbursement (say, organ transplantation) will find their choices limited by budget-driven service rationing, financial constraints, and provident gatekeepers. In such a system, policymakers and cost-conscious patients and payors may view as an insupportable extravagance a doctrine requiring physicians to spend more time engaging in more extensive dialogues with patients about alternatives that are no longer practically available to them, dialogues that are (or may seem) resistant to change, ${ }^{170}$ that often occur after the crucial decision has already been made, ${ }^{171}$ and that seem to have little observable effect on ultimate treatment decisions. They are likely to search instead for legal and other changes designed to elicit informed consent more quickly and cheaply, while reaffirming and retaining (if possible) the normative commitments that the doctrine now represents.

\section{NEXT STEPS}

There are a number of ways in which policymakers might conduct this search. I shall briefly discuss four. They should conduct a systematic costeffectiveness analysis of informed consent. They should seek better techniques for communicating information about treatment risks. They should differentiate and contextualize informed consent doctrine by distinguishing the varying

consent laws were among the new and expanding liability doctrines that played a significant role in the increase in malpractice costs during the 1970's. DANZON, MEDICAL MALPRACTICE, supra note 105, at 7677. This perception, whether justified or not, may have contributed to the distorted impressions of informed consent law "in the mind" of many physicians. But see Patricia M. Danzon, The Crisis in Medical Malpractice: A Comparison of Trends in the United States, Canada, the United Kingdom and Australia, 18 LAW, MED. \& HEALTH CARE 48, 53 (1990) (malpractice claims continuing to rise in United States despite lack of recent major doctrinal shift).

169. See infra notes $174-75$ and accompanying text.

170. KATZ, supra note 1 , at $28-29$.

171. See supra note 135 and accompanying text. 
significance and consequences of informed consent in diverse settings. And they should facilitate the ability of organized patient groups and providers to contract explicitly about the appropriate levels and other features of informed consent, just as they will be contracting about other aspects of their treatments.

\section{A. Cost-Effectiveness Analysis}

Under conditions of scarcity in health care resources, how demanding - and thus how costly — should the informed consent requirement be? The analysis in Part III comparing the doctrine's scope and consequences in the health care setting with those in other areas of tort law in which analogous doctrines exist helps to sharpen this question. But because the question is a normative one, descriptive and comparative analyses alone cannot fully answer it. In addition, empirical analysis must be conducted and some difficult normative choices, which will be illuminated but not fully resolved by that analysis, must be made.

Consider the fact that a more rigorous informed consent doctrine seeking to produce a more meaningful dialogue between physicians and patients about treatment decisions is almost certain to increase the information costs associated with the decisions-mainly the additional time required for highpriced physicians to communicate with patients about treatment risks, benefits, and alternatives. The actual magnitude of these additional information costs, of course, will depend on the size of the "informed consent gap"-the difference between the law in action and the law in books-that we are prepared to tolerate. The more we seek to close this gap by more closely conforming the law in action to the law in books, the higher the information costs will be. Talk, especially busy doctors' talk, is not cheap. Genuinely probing conversation, which advocates of the law in the books demand, is dearer still. This is especially so when each of the parties, albeit for different reasons, may be deeply ambivalent about conducting it in this manner.

A comprehensive analysis, of course, cannot confine itself to any narrowly defined conception of cost, such as the direct information costs just discussed. It must also consider other kinds of costs, which may be more difficult to measure but at least as important. These include the mental and psychic effort that patients must expend in order to comprehend the information and deal with the emotional stress that it may cause, and the effects of the disclosed information on patients' actual treatment decisions and hence on treatment outcomes, which represent the costs and benefits that are probably most salient to patients. ${ }^{172}$ Finally, such an analysis must be sensitive to the likelihood

172. This information may cause a patient to make a choice that increases costs to the system (as when a patient selects additional treatment rather than the "do nothing" option) or one that reduces the system's costs (as when a terminally ill patient decides to forgo additional life support). 
that some communication that the physician views as a cost may be viewed by the patient as a benefit. ${ }^{173}$

Equally important, a comprehensive analysis must consider the benefits of different levels of information. Some studies indicate, for example, that patients who repose greater trust in their physicians and those who better understand their disease processes and therapies actually achieve superior outcomes. ${ }^{174}$ In addition, such patients are less likely to bring malpractice actions. ${ }^{175}$ They may also experience other benefits, such as greater feelings of competence and control, that are more difficult to isolate and quantify but are nonetheless precious.

I can find no published quantitative estimates of the costs or benefits of informed consent. ${ }^{176}$ Indeed, I know of no estimates even of what should be the most straightforward cost categories, such as the increased physician time and the associated fees needed to fill the informed consent gap. ${ }^{177}$ Any

173. This possible disjunction between cost-bearer and beneficiary is all the more reason to organize the health care payment system so that, consistent with other policy goals, those who perceive and receive benefits, including information, bear the costs of producing them.

174. Poor physician communication to patients is correlated not only with malpractice claims but, more importantly, with malpractice incidence. Ellen W. Clayton et al., Doctor-Patient Relationships, in FRANK A. SLOAN ET AL., SUING FOR MEDICAL MALPRACTICE 59-60, 64-65 (1993); see also Sherrie H. Kaplan et al., Assessing the Effects of Physician-Patient Interactions on the Outcomes of Chronic Disease, 27 MED. CARE S110, S122 (Supp. 1989) (physiological and functional condition improved for patients coached to ask more questions and participate in care decisions); Don A. Rockwell \& Frances Pepitone-Rockwell, The Emotional Impact of Surgery and the Value of Informed Consent, 63 MED. CLINICS N. AM. 1341, 1350 (1979) (arguing that informed consent incorporates psychotherapeutic techniques useful to prevent and/or treat postoperative psychological complications); Wallace, supra note 145, at 32 (even patients who did not desire additional information from their physicians exhibited a therapeutic benefit). For the therapeutic benefit of information conveyance generally, see Lawrence D. Egbert et al., Reduction of Postoperative Pain by Encouragement and Instruction of Patients, 270 NEW ENG. J. MED. 825, 826 (1964) (patients informed about postoperative pain and self-relief techniques prior to surgery required significantly less pain relief medication than patients not given such information). But cf. Terence C. Wade, Patients May Not Recall Disclosure of Risk of Death: Implications for Informed Consent, 30 MED. SCI. L. 259 (1990) (54\% of cholecystectomy patients did not recall after discharge being informed of risk of death, though they cited the specific risk of death correctly on preoperative questionnaire; no therapeutic difference between those who could and could not remember).

175. Robyn S. Shapiro et al., A Survey of Sued and Nonsued Physicians and Suing Patients, 149 ARCHIVES INTERNAL MED. 2190, 2194 (1989) (doctors and patients surveyed agreed that improvement in communication is best way to prevent suits); J.K. Avery, Lawyers Tell What Turns Some Patients Litigious, MED. MALPRACTICE, July/August 1986, at 35 (insurance defense lawyers cited physician communications and attitudes as primary factor in $70 \%$ of filed claims). But see Marlynn L. May \& Daniel B. Stengel, Who Sues Their Doctors? How Patients Handle Medical Grievances, 24 LAW \& SoC'Y REV. 105, 116 (1990) (patient perception of patient-physician relationship does not predict patient choice to sue); $c f$. DANZON, MEDICAL MALPRACTICE, supra note 168, at 76-77 (expansion of informed consent laws in United States during 1970's led to higher frequency and severity of medical malpractice claims); $D$. Dewees et al., The Medical Malpractice Crisis: A Comparative Empirical Perspective, 54 LAW \& CONTEMP. PROBS. 217, 244 (1991) (more stringent requirements for informed consent in Canada have significantly increased frequency of medical malpractice claims).

176. Furthermore, my inquiries to a number of physician organizations have been unavailing. Even a recent article with a promising title contains no such estimate. See Mark Fajfar, An Economic Analysis of Informed Consent to Medical Care, 80 GEO. L.J. 1941 (1992).

177. One might begin by using the tapes of conversations from the Waitzkin study, supra note 101, to ask a panel of respondents about perceived deficiencies in those conversations and what would have been required to remedy those deficiencies. 
estimate, of course, will be arbitrary and vulnerable to criticism given the lack of good data, but some initial efforts could produce at least rough orders of magnitude from which we might begin to assess the doctrine's costeffectiveness. While the estimation task will be difficult, there is no reason in principle why it cannot be done.

The most obvious approach would attempt to measure the time and cost parameters directly. For example, one might survey physicians frequently involved in obtaining informed consent and ascertain the average amount of time consumed by the dialogue under current practice, ${ }^{178}$ the imputed cost for a unit of their time, ${ }^{179}$ and the number of such dialogues that occur during a given period. One might then ask physicians (or otherwise estimate) how much additional time would be required (in some reasonably well-defined sense) ${ }^{180}$ to improve the quality of these dialogues. ${ }^{181}$ From this information, one could begin to develop some aggregate cost estimates for various reform options. ${ }^{182}$

178. See Mark \& Spiro, supra note 101, at 778 (time estimates for colonoscopy discussion); Waitzkin, supra note 101, at 2442 (5\% of physician-patient encounter time was spent on general information giving by physicians).

179. Although physicians are ordinarily paid by procedure, a large component of the fee compensates for the time required for the procedure.

180. Some of the empirical research on reforming informed consent could be used to develop operational measures of improvement, such as scores on patient responses to questions designed to elicit and gauge their recall and comprehension. See supra note 134.

181. One might also compare informed consent practices in fee-for-service and capitation practice settings. The latter, operating on a fixed fee basis, must absorb the costs of providing informed consent, at least in the short run, while the former can pass them on to patients in the form of higher fees. If physicians in capitation plans engage in more meaningful informed consent discussions, such behavior might indicate that they view doing so as cost-effective. I am indebted to Professor Akhil Amar for this suggestion.

182. The first step in the analysis of cost-effectiveness would be to estimate the additional time required to obtain a genuine, meaningful informed consent discussion. Several earlier studies have taken a stab at this. See, e.g., Mark \& Spiro, supra note 101, at 778; Waitzkin, supra note 101, at 2442.

Without any pretense of empirical rigor or analytical precision, I decided to pose this question to several eminent, ethically reputable surgeons and anesthesiologists of my acquaintance who are associated with Yale-New Haven Hospital and the Yale University School of Medicine. Each fully subscribes to the importance of informed consent but each believes (based on many professional discussions and some readings on the subject) that most of the conversations and form-signings that now pass for informed consent in the profession are ritualistic and largely meaningless to the patient. I asked them the following question: Compared to the existing practice of informed consent, how much longer would it take on average to conduct the kind of meaningful dialogue with patients about the risks of surgery (e.g., infection, drug side effects, and other possible mishaps) that you believe the doctrine was meant to produce? While emphasizing that averages are meaningless when dealing with a wide variety of patients with diverse medical conditions, two of these physicians responded that on average at least fifteen minutes more per patient would be required. Interview with Dr. Sherwin Nuland, Associate Clinical Professor of Surgery, Yale University School of Medicine, in New Haven, Conn. (Mar. 5, 1993); Interview with Dr. Jonathan Katz, supra note 139. A third said that he would not do anything differently and estimates that he averages forty-five minutes per case on informed consent. Interview with Dr. Richard Gusberg, Professor of Surgery, Yale University School of Medicine, in New Haven, Conn. (Mar. 5, 1993).

After estimating additional time per procedure, the next step would be to assign a dollar value to that time, on the theory that although physicians are ordinarily paid by procedure rather than by the hour, the fees for particular procedures will eventually reflect any additional time required to make consent better informed. See supra text accompanying notes 100-02. Ideally, one would want the estimate to take account of the different fees charged for different procedures. Still, a serviceable estimate might nevertheless be 
Another approach would draw on cross-state or cross-national analyses of the nature and consequences of different informed consent doctrines or practices in countries whose informed consent laws are more tailored to conditions of resource scarcity than is ours, but which are otherwise roughly comparable in terms of standard of living and health care. It might be instructive, for example, to compare U.S. approaches with those in continental Europe ${ }^{183}$ in the U.K. ${ }^{184}$ and especially in Canada, ${ }^{185}$ which shares with the United States a common law heritage and a similar medical profession, albeit one that places much more emphasis on primary care and relies on altogether different financing arrangements. ${ }^{186}$ As I noted earlier, cross-

developed by using cruder but more readily available data, say, average surgeons' fees or income, or the total number of surgical procedures performed in the United States. To the extent that the data permit, additional refinements should be made. For example, the analysis should distinguish office time from operating room time, surgical procedures from other medical interventions to which the doctrine ought to apply, informed consent obtained by surgeons from that obtained by surgical anesthesiologists, and such direct costs of more meaningful informed consent from any indirect costs such as increased patient anxiety. See supra text preceding note 172 . One might also try to account for the possibility that as patients become better informed about risks and alternatives, informing them will become less costly. Interview with Dr. Jay Katz, Elizabeth K. Dollard Professor Emeritus of Law, Medicine and Psychiatry, Yale Law School, in New Haven, Conn. (June 7, 1993).

183. To generalize, the doctrine in continental European countries sets forth more stringent disclosure standards than does the rule in the United Kingdom, see infra note 184, but the continental European approach is still more deferential than the Canterbury standard used in many U.S. states. See Dieter Giesen \& John Hayes, The Patient's Right To Know-A Comparative View, 21 ANGLO-AM. L. REv. 101, 110-12 (1992).

184. The British courts do not recognize a doctrine of informed consent per se; instead, they treat negligent disclosure simply as one species of medical malpractice. SHEILA MCLEAN, A PATIENT'S RIGHT To KNOW 102 (1989). In a 1985 House of Lords decision, the United Kingdom pointedly rejected the "reasonable patient" standard of informed consent that was adopted in the United States in Canterbury v. Spence, 464 F.2d 772 (D.C. Cir. 1972), and that remains dominant here. Instead, it adopted a standard that essentially demands only the disclosures that a "reasonable physician" would make; she need not conform to the predominant practice but only to a responsible body of medical opinion. The House of Lords also endorsed a "therapeutic" nondisclosure privilege. Sidaway v. Board of Governors of Bethlem Royal Hosp., [1985] 2 W.L.R. 480. This approach was affirmed in Gold v. Haringey Health Authority, [1987] 3 W.L.R. 649. The Australian doctrine seems more open to subjective standards than the continental European and closer to that in the more patient-oriented U.S. jurisdictions. Giesen \& Hayes, supra note 183, at 121.

Sidaway's narrower conception of informed consent seems inevitable in a system like Britain's, which long ago decided both to socialize and to limit sharply most health care costs. Having subordinated patients' preferences to the system's fiscal constraints, the United Kingdom cannot allow those preferences to control at the level either of informed consent processes or of specific treatment choices. See Robert Schwartz \& Andrew Grubb, Why Britain Can't Afford Informed Consent, HASTINGS CENTER REP., Aug. 1985, at 22-23.

185. Canadian informed consent law more closely resembles that in the United States than that in the United Kingdom. The leading case is Reibl v. Hughes, 2 S.C.R. (Can. 1980), which firmly placed most Canadian informed consent doctrine within a negligence framework while also adopting an objective decision-causation test. Some analysts have attributed some of the increase in medical malpractice claims in Canada to the standards adopted in Reibl. Danzon, supra note 168 (citing D. DEwEES ET AL., CANADIAN MEDICAL MALPRACTICE LIABILITY: AN EMPIRICAL ANALYSIS OF RECENT TRENDS (1989)). In a study of one province, spanning the late 1970's and early 1980's, informed consent claims constituted $0.9 \%$ of total malpractice claims filed with Canadian insurers, and $1 \%$ of their costs. Surgery constituted $14.5 \%$ and $15 \%$, respectively; wrong diagnosis $4.1 \%$ and $5 \%$, respectively, and unnecessary treatment $0.3 \%$ for each. See LIABILITY AND COMPENSATION IN HEALTH CARE: A REPORT TO THE CONFERENCE OF DEPUTY MINISTERS OF HEALTH OF THE FEDERAL/PROVINCIAL/TERRITORIAL REVIEW ON LIABILITY AND COMPENSATION ISSUES IN HEALTH CARE app. A at 42, tbl. 9 (1990).

186. See, e.g., Theodore R. Marmor \& Jerry L. Mashaw, Northern Light: Canada's Lessons for American Health Care, 3 AM. PROSPECT 18, 18-19 (1990). The fact that so many Canadian physicians provide primary care makes the informed consent process there somewhat easier to implement because of 
national comparisons of physician-patient interactions in very different health care systems nevertheless indicate some striking behavioral similarities. ${ }^{187}$

As noted earlier, the outcome of a cost-effectiveness analysis of informed consent is not preordained. The analysis might condemn the existing "law in books" version of informed consent envisioned by its most idealistic proponents, the "law in action" version practiced by busy and often skeptical physicians and by passive, deferential patients, or both. Such an analysis might favor a return to professional custom as the standard for disclosure, or a broader "therapeutic defense," or a narrower definition of "material risk," or a more rigorous requirement for proving "decision causation." It might argue instead (or in addition) for an educational strategy in which patients would be encouraged to question more aggressively. This approach would rely more on a physician's duty to ascertain and respond fully to patients' actual and idiosyncratic concerns and less on the physician's duty to cover affirmatively what she thinks a patient would want to know. ${ }^{188} \mathrm{~A}$ related reform would be to strengthen the doctrine by requiring the physician to ascertain and ensure the patient's understanding, rather than defining the obligation simply in terms of reasonable disclosure. ${ }^{189}$ For each of these approaches, it would of course be important to assess the likely costs of securing these benefits.

The analysis might have a number of other outcomes. Notwithstanding the magnitude of the informed consent gap, the analysis might affirm the desirability of existing informed consent practice if the law in action turns out to be a better guide to the level of informed consent that society actually prefers and is willing to pay for than the law in books. In this view, the informed consent gap would not necessarily be regarded as a cause for regret;

their more regular contact with patients.

187. See supra note 153 and accompanying text.

188. See Joseph Goldstein, For Harold Lasswell: Sonte Reflections on Human Dignity, Entrapment, Informed Consent, and the Plea Bargain, 84 YALE L.J. 683, 690-98 (1975) (elaborating on this point).

189. While most courts accept a signed informed consent form to justify a presumption that "the patient understood and consented" to the procedure, e.g., Hondroulis v. Schumacher, 553 So. 2d 398, 417 (La. 1988); cf. Cross v. Trapp, 294 S.E.2d 446, 460 (W. Va. 1982) (holding that form must be sufficiently detailed for presumption to hold), some courts have at least "left the door open" to refuse to apply this presumption. Meisel, supra note 94, at 117; see also Demers v. Gerety, 515 P.2d 645, 648 (N.M. Ct. App. 1973) (holding that patient's grogginess from medication and later inability to recall signing consent form established lack of competency to consent). One court has found that a patient's failure to read the form before signing does not constitute contributory negligence. Keomaka v. Zakaib, 811 P.2d 478, 486 (Haw. App. Ct.), cert. denied, 841 P.2d 1075 (Haw. 1991). Some legislation requires that information be provided in reasonably comprehensible language. See, e.g., CAL. HEALTH \& SAFETY CODE $\$ 1704.5$ (West 1990) (requiring "written summary in layman's language and in a language understood by the patient" of procedure, alternatives and risks for breast cancer treatment); WASH. REV. CODE. ANN. \$ 7.70.060(1) (West 1992) (requiring that procedure, alternatives and risks be explained in "language the patient could reasonably be expected to understand").

Though patient understanding has seldom been addressed by courts in ordinary informed consent litigation, the patient's ability to "understand, or knowingly and intelligently act upon" medical information is the touchstone of inquiry into patient competency to consent. CAL. WELF. \& INST. CODE $\$ 5326.5(\mathrm{c})$ (West 1984). Compare In re Fadley, 205 Cal. Rptr. 572, 576 (Ct. App. 1984) (patient determined unable to consent to ECT) with Conservatorship of Waltz, 227 Cal. Rptr. 436 (Ct. App. 1986) (patient competent to consent). 
instead, it would be valued as a source of information about actual costs and benefits, information that (as we have seen) is otherwise difficult to obtain. ${ }^{190}$ On the other hand, as noted earlier, the analysis might reveal that the advocates of the law in the books are correct-that closing the informed consent gap, either with a more demanding doctrine or more effective enforcement of the existing one, would in fact produce autonomy, educational, and outcomeenhancing benefits that are worth the costs.

Whatever the outcome, we would at least have paid the informed consent doctrine the compliment of taking it seriously, of attempting to think systematically about how to maximize its effectiveness. Sadly, the organized medical profession, particularly the American Medical Association (AMA), has failed to take up this challenge energetically. Rather than facilitating a constructive appraisal of informed consent doctrine, the AMA and most specialty organizations have responded to informed consent in a reactive, defensive fashion. They have generally been passive, acquiescent spectators and occasional critics, not self-motivated, constructive reformers. ${ }^{191}$

This grudging stance was not inevitable. When informed consent doctrine was gaining ground, the AMA and specialty organizations could have taken the initiative and used their considerable prestige and expertise to develop professional standards of good medical practice with respect to informed consent. ${ }^{192}$ By drawing upon the profession's understanding of physicianpatient relationships, its ethical commitment to the primacy of its patients' interests, its capacity to adduce scientific evidence about the costs and benefits of informed consent in different settings, its familiarity with alternative techniques for communicating with patients, and its ability to monitor compliance with the doctrine, these standards might well have promoted the goals and implementation strategies for which $I$ argue below. These include using comparative risk information, contextualizating and differentiating informed consent requirements, and encouraging patient-friendly contracting

190. See Peter Schuck, Legal Complexity: Some Causes, Consequences, and Cures, 42 DuKE L.J. 1, 46 (1992).

191. See Jay Katz, Informed Consent Must It Remain a Fairy Tale?, 12-13 (no date) (unpublished manuscript, on file with author). Some medical specialty groups, such as the American College of Physicians and the American Fertility Society, have been more receptive to informed consent than has the AMA. These groups, moreover, may actually be more representative of the profession today than is the AMA, whose membership now constitutes only about half of the physicians in the United States. Telephone interview with Dr. Robert Levine, Professor of Internal Medicine and Chairman of the Human Investigations Committee, Yale University School of Medicine, New Haven, Conn. (Sept. 30, 1993); see also KATZ, supra note 1, at 23-25 (tracing history of AMA's response to informed consent). For the AMA's official position on informed consent, see AMERICAN MED. ASS'N, CODE OF MEDICAL ETHICS, ANNOTATED CURRENT OPINIONS $\$ 8.08$ (1992).

192. For example, after the Califomia Supreme Court's highly controversial decision imposing liability on psychiatrists for failing to control dangerous patients, Tarasoff v. Regents of Univ. of Cal., 551 P.2d 334 (Cal. 1976), professional organizations developed guidelines and training materials to assist psychiatrists and other mental health professionals in implementing the decision. See Paul S. Appelbaum, Implications of Tarasoff for Clinical Practice, in THE POTENTIALLY VIOLENT PATIENT AND THE TARASOFF Decision IN Psychiatric PractiCE 94-108 (James C. Beck ed., 1985). 
about informed consent. But instead of enthusiastically endorsing the informed consent principle and then teaching physicians how to apply it in medically and socially fruitful ways, the organized profession has largely abdicated this crucial creative function to legal institutions that are relatively ill-situated to perform it: private tort litigation conducted by self-interested litigants on the basis of narrow, often atypical fact situations, and adjudicated by courts and juries that know little about the complexities of medical practice. ${ }^{193}$ If the medical profession is unhappy with the law of informed consent (as it apparently is), it partly has itself to blame.

\section{B. Communicating Risk Information}

The principal goals of informed consent doctrine-to promote and protect patient autonomy and to improve the quality of both patients' and physicians' treatment decisions-cannot be achieved unless the information about the risks associated with various treatment (and nontreatment) alternatives is reliable ${ }^{194}$ and is communicated in a fashion that is intelligible and meaningful to patients. This much is obvious. Nevertheless, as already noted, the studies and commentary on informed consent in action suggest that it often fails even this minimal test. Many physicians discuss risk in a more or less perfunctory manner and without much regard to how well the patient comprehends the information. Many patients appear to understand little of the risk information and, shortly after the discussion, to recall even less. ${ }^{195}$

While many factors contribute to this failure, an important one is the language and concepts that physicians use to characterize the risks to patients. The physician's options are limited, and each is problematic to some degree. Should she employ general terms connoting the magnitude of the risk (characterizing it, for example, as "high," "low," "modest," "insignificant"), the patient will have little basis for knowing what the physician means by this and thus for making a refined risk assessment. Instead, the physician might attempt to use more specific language, employing more exact quantitative measures (expressing risk, for example, as a numerical percentage or statistical probability). Such language, however, may create a spurious and misleading impression of precision, while its abstractness-its remoteness from any referent that is real or palpable to the patient-may render it useless as a practical tool of rational decisionmaking. Alternatively, the physician may retreat to a more ambiguous formulation of the risk (a statement, for example,

193. One might also look to the medical schools and teaching hospitals to instruct new physicians in how to communicate more effectively with patients. Although certain physician disclosure patterns have indeed changed over time, see supra note 131 , medical education may not be as effective in altering these patterns as one might hope. See supra note 143.

194. See supra text accompanying note 84 .

195. See supra notes $129-41$ and accompanying text. 
that a medication "may" cause abdominal bleeding), but such a formulation, while true enough, gives little or no guidance to the patient.

But the inadequacy of these conventional ways of talking about risks goes well beyond the difficulties of describing the magnitude of a risk to individuals who are not accustomed to thinking quantitatively about risk. ${ }^{196}$ To the patient, the risk's nature and quality - the kind of pain she may feel or the loss of function she may suffer, for example-may be even more salient. These risk attributes, however, are even more difficult for the physician to convey because they entail much that is either ineffable or highly subjective. Under the best of circumstances, then, communicating effectively about risk is inherently problematic. When individuals who are trained not as dialogicians but as scientists must attempt in a busy, time-constrained clinical context to communicate complex risk information to anxious patients who are not accustomed to stochastic modes of thinking, it is hardly surprising that failure is so common.

Still, of all the formidable obstacles to genuine informed consent in health care, this one seems relatively tractable to reform. To make risk information more meaningful to patients, physicians need not transform their selfconceptions or roles, nor incur new time or other costs; they need only to change how they describe risk to patients. Suppose that physicians were to characterize risks to patients not in one of the absolute, more or less quantitative forms mentioned above but rather (or in addition) in explicitly comparative terms-that is, in terms that encourage the patient to assess the medical risk in light of other risks that are more familiar to her, risks that she has some basis for, and experience in, evaluating. For example, the physician might compare the medical risk to the risk of certain types of common accidents or other adverse outcomes (e.g., collisions from driving at night, lung cancer from smoking, complications from drinking alcohol while pregnant) about which patients are more accustomed to appraising and making explicit or implicit choices. Might patients find this kind of information more assimilable and meaningful? Would it enhance the rationality of their assessments of medical risks and, hence, improve the process and substance of informed consent?

While answering these questions in the affirmative, I acknowledge that formulating and applying comparative risk information is problematic. I do not mean to suggest that how people perceive and assess the risks they encounter in everyday life are, or should be, dispositive of their decisions about medical risks. Quite the contrary. A threshold issue concerns whether accurate comparative risk information can be made available to physicians in a form that they can then use in their discussions with patients. Currently, most

196. See the discussion and sources cited in STEPHEN G. BREYER, BREAKING THE VICIOUS CIRCLE: TOWARD EFFECTIVE RISK REGULATION (1993). 
physicians are probably ill-equipped to make risk comparisons unless they are supplied with the underlying comparative data. Indeed, even "experts" are subject to many of the cognitive errors concerning risk that laypeople, including patients, are likely to commit. ${ }^{197}$ Fortunately, however, analysts who seek to improve public perceptions and assessments of risk are increasingly compiling and publishing this kind of information, usually in order to demonstrate how irrational such assessments can be when they are not conducted in a more comparative, contextualized framework. ${ }^{198}$

There is no reason in principle why health care physicians cannot be supplied with comparative risk information that is systematically designed to be used in conversations with patients. Nor would the information supplied to physicians have to be particularly compendious or complex. At a minimum, the number of comparisons need be no larger than the number of descriptive categories that physicians already use in discussing risk with patients. If a physician would ordinarily classify medical risks in, say, four relatively imprecise categories (as very low, low, medium, or high, for example) for purposes of conversing with a patient, she need only supply the patient with four sets of comparisons in order to make that conversation more meaningful to the patient than it would have been otherwise-although more discriminating risk categories (and hence more meaningful comparisons) would probably be even better. Alternatively, if the physician would otherwise discuss a medical risk with a patient by assigning a specific statistical probability to the possible outcome in question, then only one set of comparisons is needed to improve the quality of this discussion.

Supplying comparative risk information to patients entails additional dangers. Even if the physician possesses the relevant comparative risk information, her attempts to translate medical risks into other kinds of risks might nevertheless confuse and perhaps mislead patients. After all, attitudes toward the acceptability of different risks vary from person to person. Indeed, they also vary for any given individual, depending on many factors: the source of the risk, whether the individual thinks that it is under her control and thus a matter of voluntary choice, its novelty or familiarity, its catastrophic potential, its painfulness, the possible benefits to be gained by incurring it, its relation to self-identity and morality, and the time when the feared outcome

197. See JUDGMENT UNDER UNCERTAINTY, supra note 24 , at 133-51.

198. In a recent article, for example, the authors present various causes of mortality in just such a form, explicitly comparing the annual death rate per million from asbestos exposure in schools (0.0050.093 ) to the rate for whooping cough vaccination (1 to 6); aircraft accidents (6); high school football (10); childhood drowning (27); pedestrians, from motor vehicle accidents (32); accidents to children in the home (60); and long-term smoking (1200). Mossman et al., supra note 166, at 299, tbl. 2. This example, as well as other analogous ones, are discussed in BREYER, supra note 196, at 13. See also Bruce N. Ames et al., Ranking Possible Carcinogenic Hazards, 236 SCIENCE 271 (1987); Samuel S. Epstein \& Joel B. Swartz, Technical Comment, Carcinogenic Risk Estimation, 240 SCIENCE 1043 (1988); Bruce N. Ames \& Lois S. Gold, Response, 240 SCIENCE 1045 (1988) (responding to Epstein and Swartz). 
will occur. ${ }^{199}$ Simple equivalences, therefore, are likely to be incomplete; an assertion that the risk from a particular medical procedure is lower than, say, the risk of dying in an automobile accident or the risk of contracting cancer from the stratospheric radiation encountered in flying may raise as many questions for the patient as it answers. Comparative risk information may also be incomplete and thus potentially misleading if the comparisons relate primarily to a risk's magnitude rather than to its more qualitative dimensions, which may be more important. Such comparisons might exacerbate the already strong tendency of "hard" aspects of risk information, such as magnitude, to eclipse the "softer" ones, such as quality-of-life effects.

While conceding these hazards in dispensing comparative risk information, one must also acknowledge that the risk discussions that now pass for informed consent are very unsatisfactory in advancing genuine patient autonomy and rational decisionmaking. Given this status quo, it is difficult to escape the conclusion that discussing risk in comparative terms would, on balance, help the patient think more clearly about medical risks before giving or withholding her consent to treatment. As the quantity and quality of comparative risk information increases, those with a stake in enhancing the informed consent process-health care payors, consumer organizations, and provider groups-should exploit that information by customizing it to the needs of the informed consent process, making it available to clinicians in user-friendly formats, and helping them to deploy it in their dialogues with patients. In doing so, these groups can draw upon recent work that presents quantitative and comparative information in imaginative ways to facilitate greater understanding by people not accustomed to thinking numerically or statistically. ${ }^{200}$

The infusion of comparative risk information into physician-patient discussions is one technique to enrich an informed consent process that is, by most accounts, impoverished by a lack of context within which patients can exercise meaningful choice about difficult options. But the goal of further contextualizing informed consent-both the process and the legal doctrine that regulates it-is one that can be pursued in a number of other ways as well. The following two subsections suggest several additional approaches.

\section{Contextualizing and Differentiating Informed Consent}

We have seen that courts (and to some extent, legislatures) have insisted on more meaningful informed consent in medical treatment while tolerating

199. See generally William W. LowRANCE, OF ACCEPTABle RiSK: SCIENCE AND THE DETERMINATION OF SAFETY 75-102 (1976).

200. See, e.g., EdWARD TUFTE, THE VISUAL DisPlay of QUANTITATIVE INFORMATION (1983). Citing Tufte, Carol Rose makes a related point in connection with the rhetoric of environmental protection. Carol M. Rose, Environmental Lessons, 27 LOY. L.A. L. REV. (forthcoming 1994). 
less demanding - but still robust, by traditional standards-forms of consent in product sales and other areas of risk creation. This doctrinal heterogeneity bespeaks a recognition that the notion of consent has different meanings and normative resonances in different contexts. Unfortunately, this recognition has not always penetrated the domain of informed consent proper, where the doctrine remains largely monolithic and noncontextual (except insofar as it employs "reasonableness" terms and contains certain exceptions to the general duty to disclose). In this respect, at least, the Supreme Court of California's very recent Arato decision calling for and evidencing a "sensitivity to context" is a welcome development. ${ }^{201}$

The ongoing cigarette litigation vividly illustrates the importance of contextualizing informed consent. ${ }^{202}$ Despite decades of litigation and unusually strong evidence that the cigarette manufacturers' products have contributed substantially to the approximately 400,000 deaths annually that the Surgeon General attributes to smoking, the cigarette industry has managed to defeat these claims almost completely; ${ }^{203}$ the defendants still have yet to pay a single cent in damages. $^{204}$ In the cases that have gone to trial, the industry's success has rested largely on defenses of assumed risk and contributory fault, which in this context amount to much the same thing: informed consent. It is remarkable that the industry was able to escape liability during a decade in which health consciousness grew rapidly and juries frequently imposed expansive tort liability on "deep-pocket" defendants whom, like the cigarette manufacturers, they found to have caused great harm. ${ }^{205}$

The manufacturers' success in this litigation was not at all preordained. Plaintiffs have deployed powerful arguments against them, such as the addictive qualities of nicotine, the blandness and inconspicuousness of the health warnings, and the expensive advertising campaigns depicting the glamour, sexuality, and athletic vigor of smokers. The plaintiffs' defeats testify not only to the adamantine resistance of the industry and the resourcefulness of its well-financed lawyers, but also to the vitality of consent as a normative commitment among American jurors-and presumably among the American people in general.

201. Arato v. Avedon, 23 Cal. Rptr. $2 d 131,139$ (1993); see also notes 71-90 and accompanying text.

202. See generally Robert L. Rabin, A Sociolegal History of the Tobacco Tort Litigation, 44 STAN. L. REV. 853 (1992) (noting absence of any significant award to plaintiffs during 35 years of tobacco litigation).

203. The exception is Wilks v. American Tobacco Co., No. 91-12, 355(B)(W), 1993 WL 325136 (Miss. Cir. May 11, 1993) (holding cigarette manufacturers strictly liable in wrongful death action on ground that cigarettes are defective and unreasonably dangerous as matter of law).

204. See David Margolick, Judge Says Hazards Make Cigarettes Defective by Law, N.Y. TMES, May 13,1993 , at A14 ("No plaintiff in a health-related case has ever collected from the tobacco industry."); Rabin, supra note 202, at 854 n.11 (noting two "close misses").

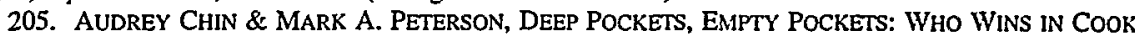
COUNTY JURY TRIALS (1985). 
We can fairly infer from this line of verdicts, then, a set of public perceptions about the conditions under which genuine consent-consent conceived as legally, and perhaps morally, compelling — can be imputed to individuals. At least where the plaintiffs had smoked after 1964 (when the famous Surgeon General's report was issued) ${ }^{206}$ or 1965 (when Congress mandated health warnings), ${ }^{207}$ juries implicitly found that some or all of the following conditions existed. At the time of consumption, smokers were reasonably well informed about the risk of cancer. ${ }^{208}$ Widespread public discussion, risk premia for life and health insurance, and growing social stigma further signalled this risk. Smokers' decisions to take the risk were not only informed choices, but were voluntary (that is, not compelled by addiction) and repeated. Viable alternatives to those choices existed (e.g., total cessation, reduced consumption, and less risky brands). Moreover, many similarly situated smokers selected those alternatives. Finally, smokers received something of value-namely physical and psychological satisfaction-in return for their choice. By trading this satisfaction off against the risk of injury, they may have exercised poor judgment (in the observer's view) but it was a judgment to which they could fairly be held, as they gained something they wanted for a risk that they appreciated. Although we cannot know precisely what was in the minds of jurors who have exculpated the industry, public opinion polls indicate that their conclusion is widely shared. ${ }^{209}$

Juries' willingness to find consent and thus deny liability under these conditions demonstrates their refusal to override smokers' individual choices in pursuit of public health goals. Juries have thus been reluctant to use tort law to require cigarette manufacturers to internalize the social costs of smoking but instead 'have seemed to favor using tort law to emphasize individuals' right to smoke and their corresponding blameworthiness and financial responsibility for the resulting harms they risk. ${ }^{210}$ This propensity is not unique to cigarette litigation. For example, I noted in Part I that leading courts often uphold the assumed risk defense in recreational risk contexts. ${ }^{211}$ Decisions denying

206. See Public Health Service, U.S. Dep't of Health, Educ., \& Welfare, Pub. No. 1103, SMOKING AND HEALTH: REPORT OF THE ADVISORY COMMITTEE TO THE SURGEON GENERAL OF THE PUBLIC HEALTH SERVICE (1964), cited in Rabin, supra note 202, at 855 n.12.

207. Federal Cigarette Labeling and Advertising Act of 1965, Pub. L. No. 89-92, § 4, 79 Stat. 282, 283 (1965) (codified as amended at 15 U.S.C. $\$ 1333$ (1988)). This legislation was followed by the Public Health Cigarette Smoking Act of 1969, which banned the advertising of cigarettes on television and radio. Public Health Cigarette Smoking Act of 1969, Pub. L. No. 91-222, § 2, 84 Stat. 87-88 (1970) (codified as amended at 15 U.S.C. $\$ \S 1335$ (1988)).

208. Indeed, there is empirical evidence that they systematically overestimate the risk. See Viscusi, supra note 121 , at 1259.

209. See Who Smokes, Whose Responsibility, AM. ENTERPRISE, May-June 1993, at 102 (83\% of respondents feel that tobacco companies should not be held responsible for smoking-related deaths).

210. Rabin, supra note 202, at 876-77 (distinguishing between public health perspective and individual rights perspective on allocating risks from smoking).

211. See supra note 50. 
recovery for injuries to professional rescuers ${ }^{212}$ also suggest that courts are willing to sacrifice possible health gains on the altar of individual rights. Conflicting approaches to cases involving injuries related to the failure to use seat belts, however, indicate the courts' continuing ambivalence on the question of personal responsibility for risky choices where important public health costs are involved. ${ }^{213}$

These cases offer an important lesson and a strategic opportunity for policymakers seeking to reform informed consent doctrine. Policymakers should ask what it is about these and other risk contexts that induces ordinary citizens (jurors) to conclude that society should impute informed consent to the victims' choices and behaviors, even in the face of grave individual harm and suffering, large social costs, and clear evidence of the defendant's causal contribution.

Although this is a difficult question, it is one that, like the costeffectiveness question, can indeed be answered, at least in principle. A satisfactory answer would include the kind of factors present in the cigarette cases and would help policymakers to evaluate informed consent doctrine and to refine its scope, tailoring it to more empirically based judgments about public attitudes regarding individual responsibility. Such an inquiry might lead policymakers to develop a more contextualized, hence differentiated, informed consent doctrine. Instead of the current unitary doctrine, there might be several doctrines with different requirements for different treatment and choice contexts. The doctrines might vary in their obligations according to the nature of the treatment, the setting in which it occurs, the number and type of alternatives that are practically available, the degree of medical uncertainty, the special capacities or vulnerabilities of the patient, and perhaps other variables.

A recent study, for example, indicates that patients retain, for long periods and with stunningly accurate recall, information that their obstetricians provide about risks, tests, and alternatives. ${ }^{214}$ This finding contrasts sharply with many other studies, which reveal that patients in other contexts recall little, even just after the medical intervention. ${ }^{215}$ If, as seems likely, the mother's happiness about the medical procedure (her child's birth) distinguishes this informed consent context from most others (in which the patient may wish to forget the procedure and everything associated with it), the distinction vividly illustrates how strongly the efficacy of informed consent depends on context and suggests how valuable a more differentiated legal doctrine could be.

212. See Gary Schwartz, The Beginning and the Possible End, supra note 16, at 672-73.

213. Compare, e.g., Lowe v. Estate Motors, 410 N.W.2d 706 (Mich. 1987) (failure to wear seat belt evidence of plaintiff's negligence) with LaHue v. General Motors Corp., 716 F. Supp. 407 (W.D. Mo. 1989) (failure to wear seat belt not assumed risk and, even if negligent, not a defense to claim of vehicle defect) and Forsberg v. Volkswagen of America, 769 F. Supp. 33 (D.N.H. 1990) (failure to wear seat belt not relevant to decedent's misconduct or plaintiff's comparative fault or failure to mitigate).

214. Githens et al., supra note 136, at 7-8.

215. See Meisel \& Roth, supra note 129 , at 288-95. 
To be sure, the doctrine need not be as particularistic and fact-dependent as the number of relevant variables mentioned above suggests. A legal doctrine can become so fine-grained, its applicability so dependent on factors peculiar to each case, that it loses all predictability. Nevertheless, it should be possible to combine the most important variables in order to identify and define a small number of stylized contexts that warrant distinctive legal treatment. ${ }^{216}$

Social policy, for example, should impute informed consent in the case of mass vaccines more readily than in the case of silicone breast implants. With vaccines, the risks are exceedingly low (although occasionally serious), the benefits are large, a patient's choice can affect numerous third parties, and the dialogic possibilities are limited. ${ }^{217}$ With implants, on the other hand, the risk-benefit ratio is more controversial, the choice is highly personal and private and does not directly affect others, and the dialogic opportunities are relatively great. ${ }^{218}$ In the latter situation, moreover, physicians might be encouraged to use third-party interlocutors who are especially sensitive to women's special concerns about implants. ${ }^{219}$ More generally, a contextualized informed consent doctrine might appropriately distinguish between elective and nonelective treatments, ${ }^{220}$ between the informed consent duties owed by a patient's family physician and those owed by a hospitalbased anesthesiologist or tertiary care subspecialist who encounters the patient only fleetingly, ${ }^{22 t}$ and between treatment through a single medical event such as surgery and treatment occurring over a long period of time. ${ }^{222}$

Other distinctions should be considered as well. The issue of unnecessary surgery, for example, is ripe for analysis from an informed consent perspective.

216. As an example of what such an inquiry might produce, consider Dr. Katz's suggestion that four specialized doctrines be established, each conforming to well defined subgroups of medical practice that merit different types of physician-patient dialogue. His subgroups are: (1) relatively minor, time-limited disorders involving relatively low-risk treatments; (2) acute disorders that require a physician to intervene immediately and to keep the patient relatively anxiety-free; (3) elective procedures or situations in which many treatment and nontreatment options are available and the decision is not rushed; and (4) conditions in which prognosis is dire and fatal outcome is a likely prospect. Jay Katz, Physician-Patient Encounters "On a Darkling Plain," 9 W. NEW ENG. L. REV. 207, 221-22 (1987).

217. Given the distinct characteristics of the vaccination context, Reyes v. Wyeth Laboratories, 498 F.2d 1264 (5th Cir.), cert. denied, 419 U.S. 1096 (1974), becomes difficult to justify. In Reyes, the court held that the vaccine manufacturer was under a duty to warn consumers of the risk of injury even though the vaccine in that case was highly effective in preventing polio and carried a risk of only a very few polio cases per million. Id. at $1282,1295$.

218. The "learned intermediary" doctrine, which requires manufacturers of medical devices to wam physicians, but not patients, of the possible dangers of their products, has been applied by courts in the context of silicone breast implants. This doctrine thus places an extra and perhaps even exclusive burden on the physician to inform the patient. See, e.g., Toole v. McClintock, 778 F. Supp. 1543, 1547 (M.D. Ala. 1991) (applying "learned intermediary" doctrine to context of silicone breast implants); Lee v. Baxter Healthcare Corp., 721 F. Supp. 89 (D. Md. 1989) (same).

219. See supra note 157 and accompanying text.

220. But cf. Pauscher v. Iowa Methodist Medical Ctr., 408 N.W.2d 355, 360 (lowa 1987) (rejecting this distinction).

221. For development of this distinction, see NULAND, supra note 20, at 258-61, 265-67; Howard Brody, Transparency: Informed Consent in Primary Care, HASTINGS CENTER REP., Sept./Oct. 1989, at 5.

222. Brody, supra note 221, at 7-9; Levine, supra note 15 , at 1230-31. 
There may be some situations in which physicians should be required to disclose not merely the existence of a reasonable nonsurgical alternative (a disclosure required under existing doctrine), but also the fact, bearing on the necessity for the procedure, that the surgery rate for it is much lower in other countries with comparable standards of health care. Notable examples of this disparity are the far higher rates of elective hysterectomies, caesarean deliveries, and tonsillectomies in the United States than in other such countries despite the failure of these higher rates to produce significantly better medical outcomes. ${ }^{223}$ Whether to require disclosure of the disparity in such situations should probably depend on how clear and unequivocal the data are. If the differential surgery rates are either uncertain or subject to plausible alternative explanations, requiring disclosure of the differentials (as distinct from disclosure of the existence of the nonsurgical alternative) may simply confuse or mislead the patient.

\section{Contracting About Levels of Informed Consent}

This kind of contextualized differentiation is attractive precisely because informed consent is a normative variable, not an empirical constant. Questions about what constitutes meaningful informed consent and how much of it is desirable cannot be satisfactorily answered in the abstract or even by recourse to research findings or reasoned intuitions about the psychology of decisionmaking. It also depends on social judgments about the efficacy of different legal and regulatory regimes, about the conditions that justify imposing responsibility on individuals for their choices, and about the appropriate balance between the costs and benefits to different people of different levels of information about different issues in different settings.

We have seen how informed consent doctrine might be affected by the various ways in which legal policymakers, operating under certain value systems or resource constraints, might strike this balance. We have also seen how different treatment contexts might warrant different informed consent

223. See H. David Banta \& Stephen B. Thacker, The Case for Reassessment of Health Care Technology: Once Is Not Enough, 264 JAMA 235 (1990) (calling for continual comparison of medical technologies to assure optimal effectiveness); J.P. Bunker, Elective Hysterectomy: Pro and Con, 295 NEW ENG. J. MED. 264 (1976) (discussing necessity, risks, and rates of hysterectomies in United States); Richard C. Dicker et al., Hysterectomy Among Women of Reproductive Age: Trends in the United States, 1970-1978, 248 JAMA 323 (1982) (discussing regional and socioeconomic differences in hysterectomy operations in United States); J.E. Wennberg et al., Changes in Tonsillectomy Rates Associated with Feedback and Review, 59 PEDIATRICS 821 (1977) (discussing decline in tonsillectomy rates in Vermont following feedback and review); Pieter E. Treffers et al., Home Births and Minimal Medical Interventions, 264 JAMA 2203 (1990) (discussing low rate of medical intervention in obstetrical care in the Netherlands). See generally LYNN PAYER, MEDICINE AND CULTURE: VARIETIES OF TREATMENT IN THE UNITED STATES, ENGLAND, WEST GERMANY AND FRANCE 124-26, 183 (1988). For a comparison of surgical and hospital practices in two similar urban settings in the northeastern United States, see John E. Wennberg et al., Are Hospital Services Rationed in New Haven or Over-Utilized in Boston?, 1987 LANCET 1185 (finding striking differences in some surgery rates, hospital utilization, and costs). 
regimes. This variability, however, goes much farther. It extends to individual preferences. Individuals are at least as likely as policymakers to differ concerning how they value the information and dialogue that informed consent rules encourage but cannot assure. As some commentators have observed, some patients seem to prefer leaving some or all medical treatment decisions to their physicians, accepting their ignorance about the risks they face but placing trust in their physicians to "do the right thing" for them. ${ }^{224}$ Others appear to act in the same way even though they may in fact simply be too intimidated or anxious to behave otherwise. Still others-I call them (us) "information junkies"-more closely approximate the conventional "rational consumer" model of decisionmaking, treating medical treatment decisions more or less like other consumption decisions with respect to the information sought. In recognition of this diversity, the informed consent analogues in other areas of tort law-product warnings and especially assumed risk-are highly differentiated. Within very broad limits, the law permits sellers and buyers, risk creators and risk bearers, to define by contract the information and risk levels that (all things considered) they prefer. ${ }^{225}$

The law of informed consent in health care could not be more different in this respect. With some relatively narrow exceptions, ${ }^{226}$ the law treats all patients and physicians the same; it posits an abstracted, objectively defined "prudent patient" as the consumer of information and the maker of choices, and conforms all physicians' legal obligations to this uniform abstraction. For these reasons, current law might not enforce contract terms providing for an informed consent standard less demanding than that which the law now imposes. In rejecting such terms, a court would probably argue categorically that a patient's pre-illness decision to forgo information must be even less well-informed than a decision about treatment made by the patient after illness strikes.

Like the "reasonable person" standard and other objective standards in tort law, the existing uniform approach to informed consent has two virtues: it is cheaper to know and to administer, and it seeks to protect patients against gross inequalities of bargaining power vis-à-vis providers. But a doctrine that treats all patients and physician-patient relationships as essentially homogeneous when in fact they are not exacts a price. Specifically, the law requires a level of informed consent that is different from the level that many consumers or groups of consumers want and for which they would be willing to pay if the choice were presented to them. The existing doctrine, then, suffers

224. See Mark \& Spiro, supra note 101; Interview with Dr. Nuland, supra note 182.

225. Examples include product warranties, limitations or disclaimers of liability by service providers and insurance contracts.

226. See Pauscher v. Iowa Methodist Medical Ctr., 408 N.W.2d 355, 360 (Iowa 1987); see supra text accompanying note 96 . 
from an ironic, if endemic, vice: it deprives patients of choice in the name of choice.

As the health care system becomes more highly organized, however, and large group purchasers of health care acquire a degree of monopsonistic power and act as proxies for their patient members, both reasons for uniformity in the level of informed consent begin to lose whatever force they have. Uniformity in such circumstances ceases to be a virtue and power inequalities are reduced, perhaps even eliminated. Where those conditions exist, the law should permit such groups to contract with providers over the appropriate features of informed consent, ${ }^{227}$ just as they are now free (within very broad limits) to bargain over the composition of the benefits package, the cost of care, credentialing of providers, freedom of choice with respect to providers, and numerous other elements of health care service delivery. Providers and patient groups might bargain over a variety of informed consent policies: standard procedures for physician-patient dialogues, options for more (or less) intensive discussions, the kinds of disclosures to be made, the presence of family members, the use of third-party interlocutors, the consent forms to be used, alternative dispute resolution, the level of damages in the event of a violation, institutional liability, and many other variables.

In order to facilitate such bargains, the law need not regulate them; it need only make clear its willingness to enforce their terms under appropriate circumstances. For example, the courts that uphold patients' claims despite contractual waivers of liability commonly stress their discomfiture with provisions like the one in Tunkl that exculpate the provider from any liability whatsoever. ${ }^{228}$ Provisions that do not go so far but instead simply alter the procedures and standards governing the communication or the parameters of any resulting litigation such as the level of damages may, and in my view should, fare better in the courts. ${ }^{229}$ Such provisions should certainly be acceptable if the patient belonged to an organization that can truly be said to have represented the interests of patients as a group..$^{230}$ The provisions should also be upheld, however, if they can plausibly be said to have advanced the

227. Some other commentators support contracting over levels of informed consent. See Clark C. Havighurst, Prospective Self-Denial: Can Consumers Contract Today To Accept Health Care Rationing Tomorrow?, 140 U. PA. L. REv. 1755, 1787 n.80 (1992); Shultz, supra note 75, at 281-83; cf. RUBIN, supra note 38 , at 75-77 (proposing contracting about levels of damages from medical malpractice generally without specific discussion of informed consent); Margaret Farrell, Revisiting Roe v. Wade: Substance and Process in the Abortion Debate, 68 IND. L.J. 269, 361 (1993) (advocating consensual process model of constitutional adjudication "permit[ting] different bargains to be struck in different courts by different parties.").

228. See Tunkl v. Regents of Univ. of Cal., 383 P.2d 441 (Cal. 1963); see also supra note 43 and accompanying text.

229. See, e.g., Mehlman, supra note 72, at 409-12. See generally William H. Ginsburg et al., Contractual Revisions to Medical Malpractice Liability, 49 LAW \& CONTEMP. PROBS. 253 (1986).

230. In this connection, the health alliance envisioned under the "managed competition" approach proposed by President Clinton could act as a sophisticated, powerful advocate for consumers. For one such version by a prominent member of the President's task force, see STARR, supra note 125. 
patient's interests, when viewed ex ante, and there is no real evidence of overreaching or lack of consent. A doctrine designed to advance patient autonomy should not, through an unrealistically demanding notion of consent, be deformed in ways that actually defeat that value.

\section{CONCLUSION}

Fiscal pressures on private and public payors have already caused farreaching changes in the health care system in the United States. These pressures, as well as anxieties about the lack of insurance coverage for many poor and middle-class Americans and concerns about international competitiveness in the private sector, are generating even more fundamental reforms. These developments will lead to a greater level of organization among both providers and patients, more cost-consciousness and regulation by payors, and some compromising of patient autonomy and pluralistic medical practice. In this milieu, every institution and practice should be closely scrutinized to ensure that it does whatever it seeks to do in a way that is better, cheaper, or both.

The doctrine of informed consent is no exception. Although no one contests its goals of patient autonomy and improved decisionmaking, its present effectiveness in achieving those goals is quite limited; indeed, its most sophisticated advocates accept this fact, even while condemning the informed consent gap, which is a measure of this failure. I have expressed serious doubts about whether, in light of certain largely intractable constraints, this gap can be closed in the way these advocates suggest (i.e., by enforcing the law in the books or by making it even tougher) and also about whether in an increasingly cost-conscious health care system it ought to be closed in this way. Instead, I suggest that informed consent be systematically analyzed (as it has not been in the past), that comparative risk information be used to render informed consent dialogues more useful to patients, and that the unitary character of the existing informed consent arrangements be abandoned in favor of doctrinal changes and contractual arrangements that can fragment, differentiate, and contextualize it. In these ways, informed consent-the law in action, in books, and eventually in the mind-can finally begin to fulfill its alluring promise. 
HeinOnline -- 103 Yale L.J. 960 1993-1994 